\title{
Defining the Incidence and Associated Morbidity and Mortality of Severe Respiratory Syncytial Virus Infection Among Children with Chronic Diseases
}

\author{
Paolo Manzoni · Josep Figueras-Aloy · Eric A. F. Simões • \\ Paul A. Checchia - Brigitte Fauroux - Louis Bont - Bosco Paes • \\ Xavier Carbonell-Estrany
}

Received: May 2, 2017 / Published online: June 26, 2017

(c) The Author(s) 2017. This article is an open access publication

\begin{abstract}
Introduction: REGAL (RSV Evidence-a Geographical Archive of the Literature) has provided a comprehensive review of the published evidence in the field of respiratory syncytial virus (RSV) in Western countries over the last 20 years. This review covers the risk and burden
\end{abstract}

Enhanced content To view enhanced content for this article go to http://www.medengine.com/Redeem/ F6E4F06044E2A44B.

Electronic supplementary material The online version of this article (doi:10.1007/s40121-017-0160-3) contains supplementary material, which is available to authorized users.

P. Manzoni

Neonatology and NICU, Sant'Anna Hospital, Turin, Italy

P. Manzoni · L. Bont

ReSViNET (Respiratory Syncytial Virus Network),

Málaga, Spain

J. Figueras-Aloy

Hospital Clínic, Catedràtic de Pediatria, Universitat

de Barcelona, Barcelona, Spain

E. A. F. Simões

Center for Global Health, University of Colorado

School of Medicine, Colorado School of Public

Health, Aurora, CO, USA

P. A. Checchia

Baylor College of Medicine, Texas Children's

Hospital, Houston, TX, USA of RSV infection in children with underlying medical conditions or chronic diseases (excluding prematurity and congenital heart disease).

Methods: A systematic review of publications between January 1, 1995 and December 31, 2015 across PubMed, Embase, The Cochrane Library, and Clinicaltrials.gov was supplemented by papers identified by the authors through March 2017. Studies reporting data for hospital visits/ admissions for RSV infection as well as studies reporting RSV-associated morbidity and mortality were included. Study quality and strength of evidence (SOE) were graded.

Results: A total of 2703 studies were identified and 58 were included. Down syndrome,

\section{B. Fauroux}

Necker University Hospital and Paris 5 University,

Paris, France

L. Bont

University Medical Center Utrecht, Utrecht, The

Netherlands

\section{B. Paes}

Department of Paediatrics (Neonatal Division), McMaster University, Hamilton, Canada

X. Carbonell-Estrany ( $\varangle)$

Hospital Clinic, Institut d'Investigacions Biomediques August Pi Suñer (IDIBAPS), Barcelona, Spain

e-mail: carbonell@comb.cat 
irrespective of prematurity and congenital heart disease (moderate SOE), immunocompromised children (low SOE), cystic fibrosis (low SOE), and neurologic conditions (low SOE) were associated with a significantly increased risk of RSV hospitalization. A number of other congenital malformations and chronic conditions were also associated with severe RSV disease (low SOE). In general, pre-existing disease was also a predisposing factor for RSV-related mortality (low SOE).

Conclusion: Severe RSV infection in infants and young children with underlying medical conditions or chronic diseases poses a significant health burden. Further studies are needed to fully quantify the epidemiology, burden and outcomes in these populations, in particular RSV-attributable mortality.

Keywords: Bronchiolitis; Comorbidity; Congenital malformation; Cystic fibrosis; Down syndrome; Immunocompromised; Neuromuscular impairment; Outcomes; Respiratory syncytial virus lower respiratory tract infection; Transplant

\section{INTRODUCTION}

Respiratory syncytial virus (RSV) is the most common cause of childhood lower respiratory tract infection (LRTI) and a major cause of hospitalization in children younger than 5 years of age worldwide [1, 2]. Nearly all children have been infected with this virus at least once by the time they are 2 years of age, and, in most previously healthy children, the infection is self-limited and responds to supportive care [3]. It is well established that certain high-risk groups, including premature infants and those with chronic lung disease (CLD)/bronchopulmonary dysplasia (BPD) and congenital heart disease (CHD), are at risk for severe disease [4-6]. Evidence also suggests that children immunocompromised through the administration of anticancer chemotherapy and especially those being transplanted [hematopoietic stem cell transplant (HSCT) recipients, bone marrow transplant (BMT) recipients, solid organ transplant (SOT) recipients] and those with Down syndrome face an increased risk of severe RSV LRTI [7-11]. Whilst CHD is common in children with Down syndrome (over $30 \%$ in those $\leq 1$ year of age) [12-14], there is evidence that children with Down syndrome without CHD are also at increased risk of RSV hospitalization (RSVH) [15]. Other infants with chronic conditions, both congenital and acquired, including chromosomal abnormalities other than Down syndrome, congenital malformations, especially pulmonary and airway anomalies, cystic fibrosis, and human immunodeficiency virus (HIV) may also be associated with an increased vulnerability to severe RSV LRTI [10, 16, 17].

The clinical and economic burden of RSV LRTI in pediatric populations at high risk of severe disease is considerable [18-22]. Studies indicate that children with underlying medical conditions and RSV LRTI are admitted to hospital for longer periods of time, have a higher requirement for oxygen therapy, and more often require hospitalization in pediatric intensive care units (PICUs) than previously healthy children with RSV LRTI [21, 22]. A greater understanding of the epidemiology and burden of RSV LRTI in these children is required in order to develop strategies to reduce the morbidity and mortality associated with the disease. This paper, which represents the sixth in a series of seven publications covering a range of topics on RSV disease-The REGAL (RSV Evidence-a Geographical Archive of the Literature) series-identifies and describes the incidence and associated morbidity and mortality of RSV infection among children with underlying medical conditions or chronic diseases that place them at high risk for severe disease.

\section{METHODS}

The primary objective of REGAL was to provide a comprehensive understanding of severe RSV disease in Western societies, defined as the United States, Canada, and Europe (including Turkey and the Russian Federation), over the last 20 years. Seven specific research questions were addressed by a panel of experts in RSV 
from the United States, Canada, and Europe. Previous publications have addressed: the overall burden and epidemiology of RSV disease [2]; the disease in premature children [4]; those with CLD [5]; CHD [6]; and long-term respiratory morbidity following RSV infection [23]. In this review, we sought to answer the following question: What is the predisposition of children with underlying medical conditions or chronic diseases (other than CLD and CHD) to severe RSV infection and related hospitalization?.

The systematic reviews undertaken to answer each research question all use the same broad methodology, which was described in detail in the first publication [2]. For the current review, due to the number of chronic conditions of interest, two separate comprehensive literature searches were undertaken in PubMed, EMBASE, and the Cochrane Library and the results combined. Both searches included studies published between January 1, 1995 and December 31, 2015. For the first literature search, we used the following general terms and limits combined with Medical Subject Headings (MeSH): "RSV" OR "respiratory syncytial virus" AND "Down syndrome" OR "trisomy 21" AND "hospitalization" OR "predisposition" OR "risk factor" AND "limits: human." The corresponding terms and limits for the second search were: "RSV" OR "respiratory syncytial virus" AND "bone marrow" OR "stem cell" OR "hematopoietic cell" OR "solid organ" OR "liver" OR "renal" AND "transplant" OR "immunodeficiency" OR "immunocompromised" OR "cancer" OR "leukemia" OR "malignancy" OR "cerebral palsy" OR "cystic fibrosis" OR "neuromuscular impairment" OR "neurological disorder" OR "special populations" AND "limits: human". For both searches, age restrictions were not employed to enable capture of studies with mixed populations of children and adults.

The inclusion criteria were studies reporting 'proven' or 'probable' RSV infection in specific populations of children (aged $\leq 18$ years): Down syndrome with or without CHD, immunodeficiency, neuromuscular impairment, cystic fibrosis, congenital airway anomalies (CAA), and other rare congenital and metabolic disorders. For completeness, studies reporting on mixed populations of healthy children and children with underlying chronic conditions/comorbidities and those including RSV immunoprophylaxis were included and the relevant data extracted where possible. Studies with the specific purpose of assessing RSV immunoprophylaxis were excluded from this systematic review. Also excluded were studies reporting solely on infants and children with $\mathrm{CHD}$ or CLD/BPD, since these high-risk groups were covered in separate publications in the REGAL series $[5,6]$. The search results were supplemented by a review of the bibliographies of key articles for additional studies and inclusion of relevant abstracts presented at key meetings. Other relevant studies published in 2016 and during the drafting of the manuscript were also included in the review, as identified by the authors.

\section{Outcomes of Interest}

In the absence of a standardized definition of severe RSV disease, we have taken this to be 'RSV infection requiring hospitalization' (RSVH) [2]. The following were outcomes of interest for this review: incidence of RSV, RSVH rates, hospital length of stay (LOS), PICU admission and LOS, oxygen requirement, need for and duration of mechanical ventilation and/or non-invasive ventilation, case fatality rates, and risk factors for severe RSV infection requiring hospital admission.

\section{Evaluation of Data}

Included publications were assessed against the Oxford Centre for Evidence-Based Medicine Levels of Evidence [24, 25] (Supplementary Material 1-REGAL Protocol). Each study was also subject to a risk of bias assessment using the RTI Item Bank for observational studies (score of $1=$ very high risk of bias; score of $12=$ very low risk of bias) [26]. No quantitative data synthesis was undertaken due to salient differences between studies in terms of design, patient populations, RSV testing, recording and availability of outcomes, and differences in clinical practice between countries and over time. 


\section{Compliance with Ethics Guidelines}

The analysis in this article is based on previously published studies and does not involve any new studies of human or animal subjects performed by any of the authors.

\section{RESULTS}

\section{Articles Selected}

From the two literature searches, 2692 potentially relevant articles were identified, of which 607 were reviewed at abstract level following initial screening of titles (Fig. 1). Screening of abstracts resulted in a further 560 articles being rejected for not meeting the inclusion criteria, predominantly for not being focused on Western countries and/or RSV. The 47 relevant studies from the literature searches were supplemented by 11 studies identified from reference lists and other sources, resulting in a grand total of 58 studies included in the review. The online supplement includes data extraction tables for all 58 studies, including evidence grades and risk of bias assessments.

\section{Incidence of RSV Infection and Outcomes Down Syndrome}

Clinical studies performed in the United States $[15,22,27]$, Canada [28], and Europe $[7,10,29-32]$ have demonstrated that children with Down syndrome are at increased risk of severe RSV disease and resulting morbidity, independent of concomitant CHD. Incidence

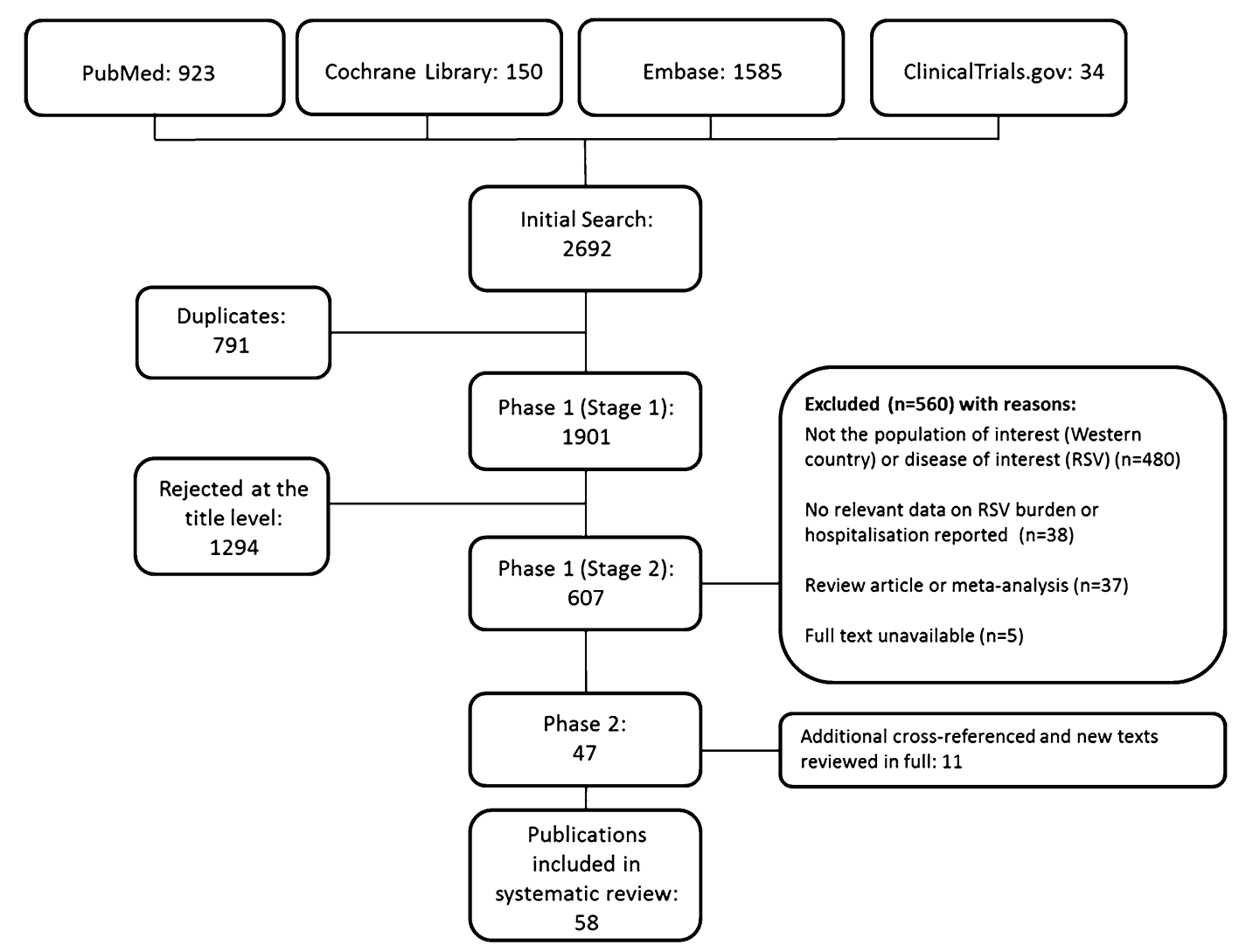

Fig. 1 PRISMA flow diagram: Incidence and burden of RSV in pediatric populations at high risk for RSV infection. $R S V$ respiratory syncytial virus. References were screened for inclusion in two Phases. Phase I screening was split into two Stages: Stage 1-based on title and, for those meeting the inclusion criteria, Stage 2-based on abstract. Those references retained after Phase 1 were assessed based on the full paper in Phase 2 


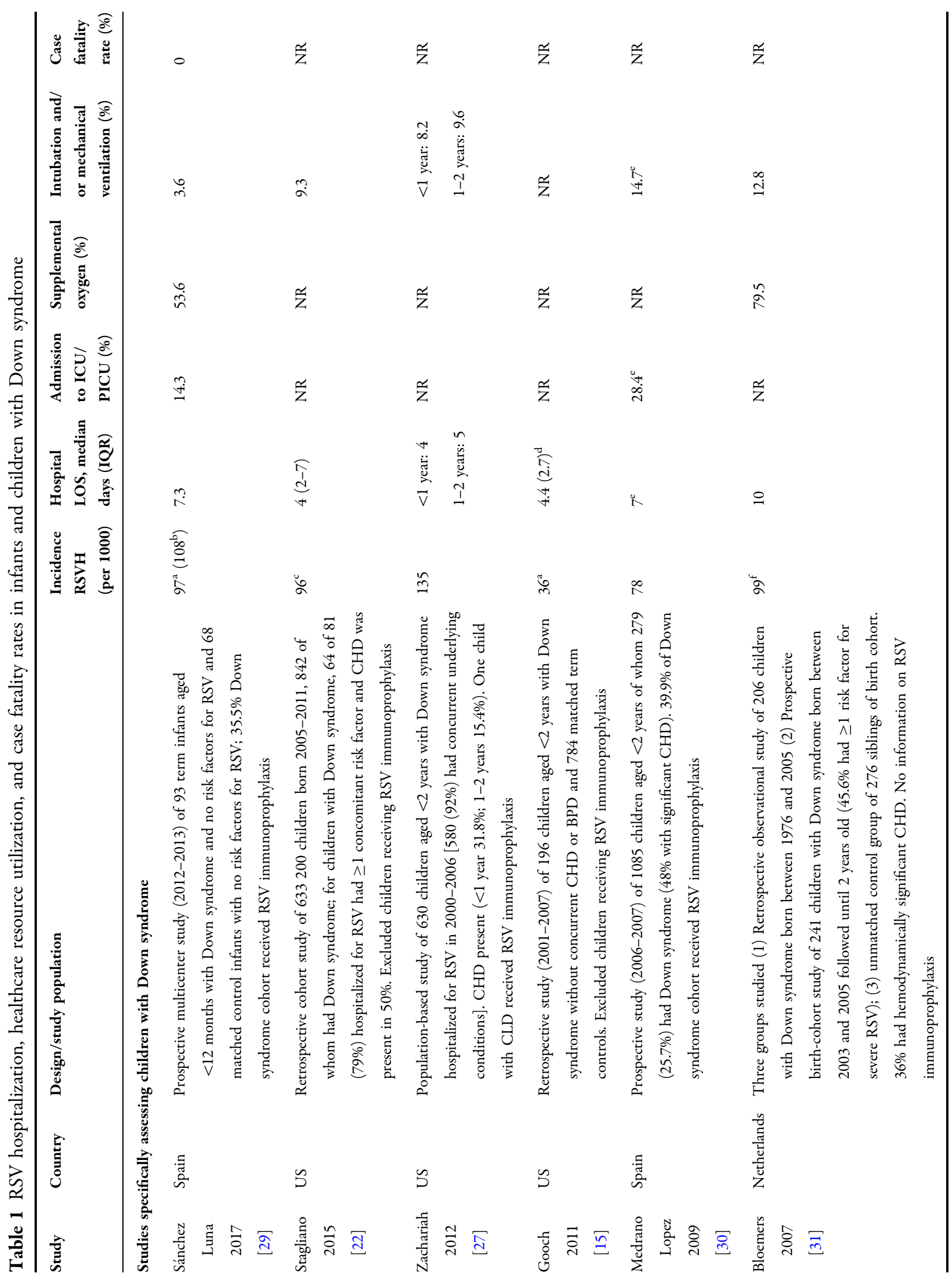




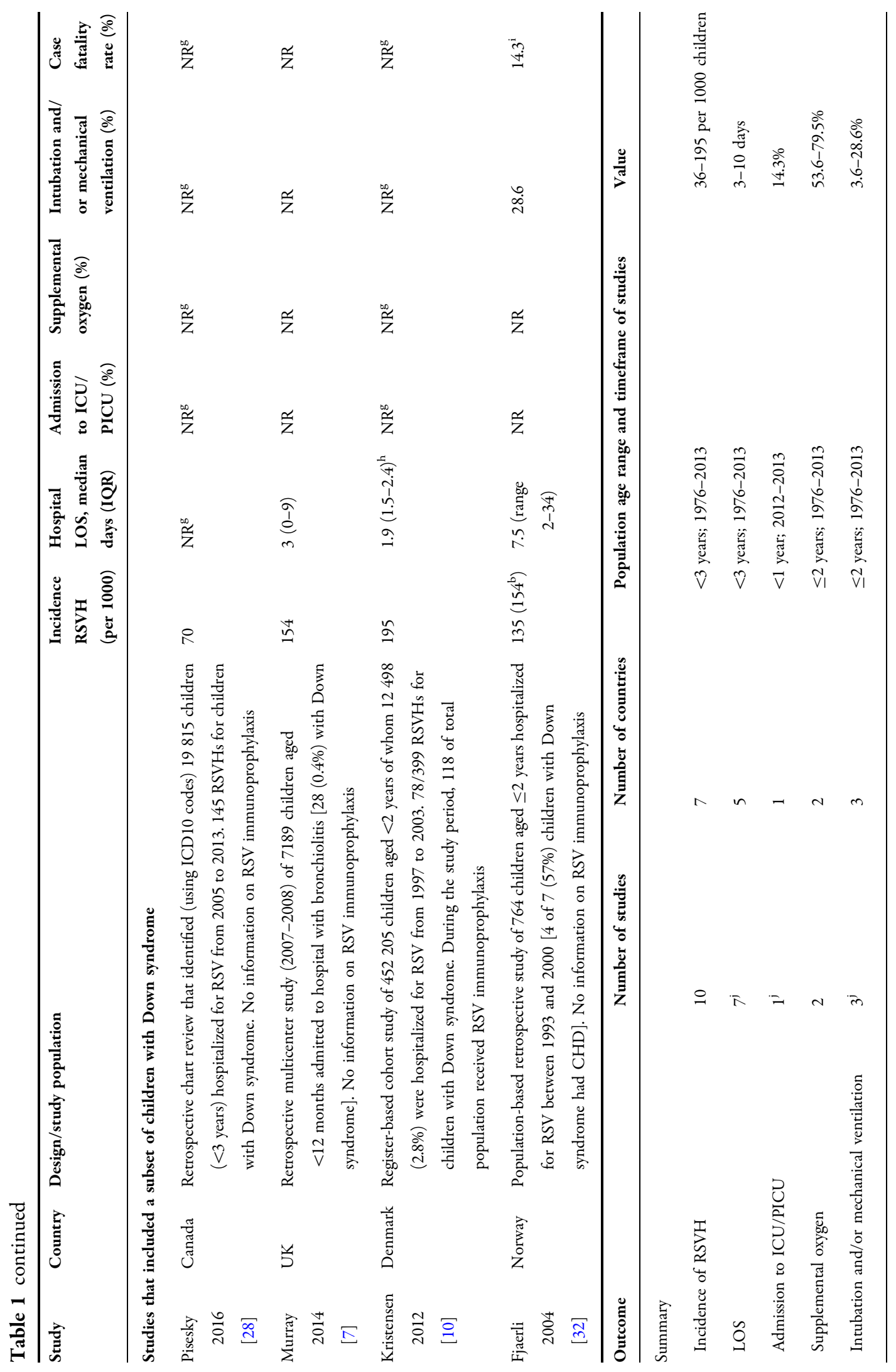




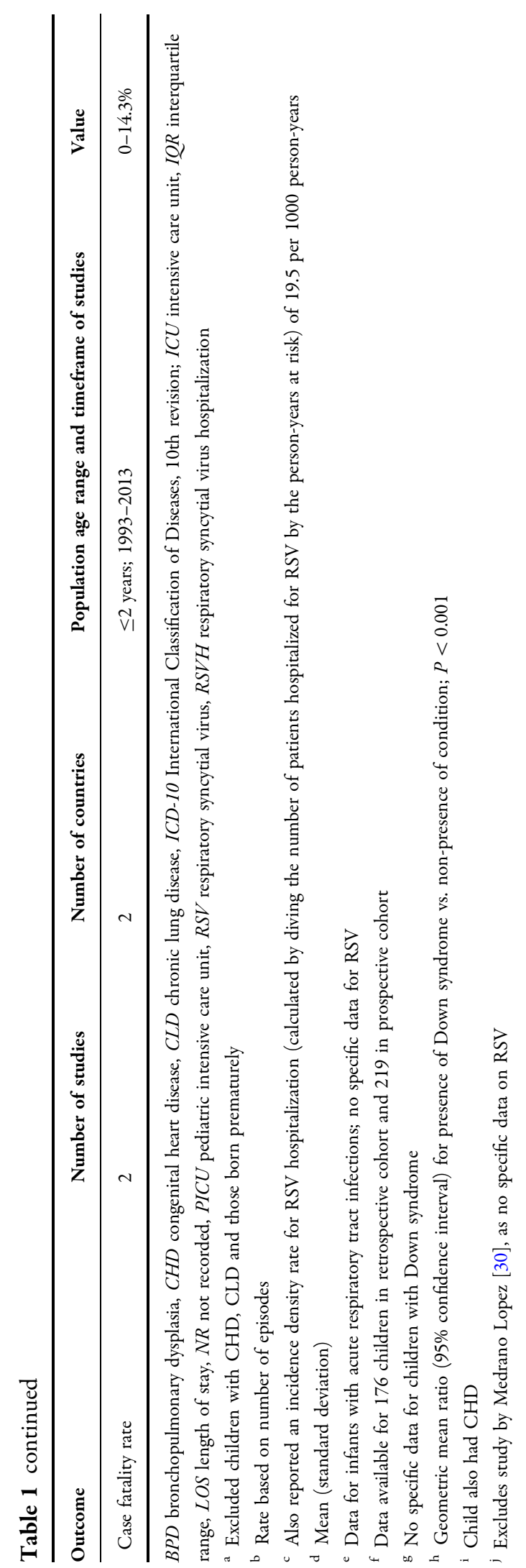

rates of RSVH ranged from 70 to 195 per 1000 children ( $<3$ years) with Down syndrome, when including those with concurrent CHD and other associated risk factors for severe RSV infection (Table 1) [7, 10, 15, 22, 27-32]. Zachariah et al. [27], using statewide data from Colorado in the US, reported a RSVH rate of 67 per 1000 child-years in children ( $\leq 2$ years) with Down syndrome compared with 12 per 1000 child-years in matched (by date of admission) children without Down syndrome [odds ratio (OR) 6.0, 95\% confidence interval (CI) 5.4-6.7]. RSVHs predominantly occurred in older children (OR 2.4, 95\% CI 1.7-3.4), with a higher proportion in boys, and were more commonly associated with CHD and pulmonary hypertension [27]. Similar findings were reported in a UK population-based birth cohort study by Murray et al. [7], which found that admission rates were higher among children aged $<12$ months with Down syndrome (154 per 1000 infants) compared with those born at term without RSV-associated risk factors (22 per 1000 infants). Down syndrome was found to significantly increase the risk of RSVH in this population [relative risk (RR) 2.5, 95\% CI 1.7-3.7] [7]. Down syndrome was also found to be a significant risk factor for RSVH in a national population-based study conducted in Denmark [ $<2$ years; incidence rate ratio (IRR) vs. otherwise healthy children $3.4,95 \%$ CI 2.7-4.4; $P<0.001$ ] [10]. In a US retrospective cohort study, it was shown that the risk of severe RSV LRTI remains high through the third year of life in children with Down syndrome versus those without the diagnosis [24-36 months: hazard ratio (HR) 5.1, 95\% CI 2.2-11.6] [22].

Down syndrome has also been shown to increase the risk of RSVH in the absence of co-existing risk factors for severe RSV disease $[15,22,27,29,31]$, in particular CHD, which has been reported in $15-57 \%$ of such children [22, 27, 30-32]. A prospective study in Spain by Sánchez-Luna et al. [29] reported a higher rate of RSVH in infants ( $<12$ months) with Down syndrome without other associated risk factors for severe RSV infection (including CHD, BPD, and prematurity) than in matched (by sex and date of birth) infants without Down syndrome and risk factors (97 vs. 15 per 1000 infants, 
respectively; $P=0.03$ ). In their combined prospective-retrospective study, Bloemers et al. [31] from the Netherlands reported an OR for RSVH of 10.5 (95\% CI 2.2-49.5) among term children ( $\leq 2$ years) with Down syndrome without any CHD in comparison to healthy controls (OR 12.6, 95\% CI 2.9-54.5, when including children with hemodynamically insignificant CHD). The study by Zachariah et al. [27] also reported a significantly elevated rate of RSVH in children ( $\leq 2$ years) with Down syndrome but without risk factors for RSV (including CHD, CLD, prematurity, pulmonary hypertension, and neuromuscular disease; 42 vs. 12 per 1000 child-years in children without Down syndrome; OR 3.5, 95\% CI 3.1-4.1), though this rate was lower than that for children with Down syndrome and associated risk factors (67 per 1000 child-years). Another US study, using a medical claims database, found a significantly higher rate of RSVH in children ( $\leq 2$ years) with Down syndrome than matched control children (by birth, gender and State), when diagnoses of CHD and BPD and those born prematurely were excluded (36 vs. 8 per 1000 children, respectively; OR 4.8, 95\% CI 1.6-14.5; $P=0.005$ ) [15]. Similarly, the US study by Stagliano et al. [22] reported an incidence density for RSVH of 12.7 per 1000 person-years in children ( $<3$ years) with Down syndrome but without risk factors (CLD, CHD, neuromuscular disease, immunodeficiency, cystic fibrosis, CAA, or prematurity) versus 2.5 per 1000 person-years in healthy children (rate ratio 5.08, 95\% CI 3.2-8.2) [22].

Children with Down syndrome spent an average of 3-10 days in hospital for RSV LRTI $[7,15,22,27,29,31,32]$. Comparative studies have shown that children with Down syndrome have a longer hospital stay than those without the condition, irrespective of the presence of other risk factors for severe RSV disease [22, 27]. In the US study by Stagliano et al. [22], children with Down syndrome had a median LOS of 4 days (5 days for those without risk factors) compared with 2 days in children without Down syndrome $(P<0.001$ for both). There was also a greater risk of requiring respiratory support, including respiratory intubation and/or mechanical ventilation, with Down syndrome (RR 5.6, 95\% CI 2.5-12.3, $P<0.001$ ). Zachariah et al. [27] also reported a significantly longer LOS for children with Down syndrome aged 1-2 years compared to those without the condition (median 5 vs. 2 days, respectively; $P<0.001)$, as well as an increased severity of disease (severity scores $>2$ on the $3 \mathrm{M}$ Health Information Systems All Patient Refined Diagnosis Related Groups severity coding scale; $<1$ year: $50.6 \%$ vs. $10.9 \%, P \leq 0.001 ; 1-2$ years: $36.5 \%$ vs. $11.0 \%, P \leq 0.001$ ), and higher rates of mechanical ventilation, particularly in older children (1-2 years: $9.6 \%$ vs. $1.7 \% ; P \leq 0.001$ ). Importantly, this effect was seen even when hospitalizations with other clinical risk factors for RSV were excluded from the analysis [27].

\section{Immunocompromised Children}

Studies undertaken in the United States $[20,33-46]$, Canada [9, 47], and Europe $[7,10,17,48-55]$ provide compelling evidence that children who are immunocompromised are at high risk for severe RSV infection. The majority of studies focused primarily on HSCT/ BMT recipients (16 of 22 studies in Table 2 ), though data were also available on SOT recipients and cancer patients undergoing chemotherapy and, to a lesser extent, children with primary immunodeficiency, HIV, and those on immunosuppressant therapy and/or corticosteroids. Incidence rates of RSV infection have been reported as high as 200 per 1000 children during an RSV outbreak among pediatric patients hospitalized for various hemato-oncological diseases in Turkey, including those who had undergone HSCT [50]. Of the studies providing information on the incidence of RSV infection in immunocompromised children, 10 of 13 reported rates of between 18 and 72 per 1000 (range 0-200 per 1000) (Table 2). There appeared to be considerable variation in the rates of RSV infection in different patient groups depending on the specific cause(s) of the compromised immune system. For example, a Spanish study by Mendoza Sánchez et al. [17] retrospectively reviewed respiratory viral infections in children aged $\leq 14$ years and found rates of RSV infection were twice as high in patients with HIV than those receiving chemotherapy for cancer (101 vs. 46 per 1000, respectively). 


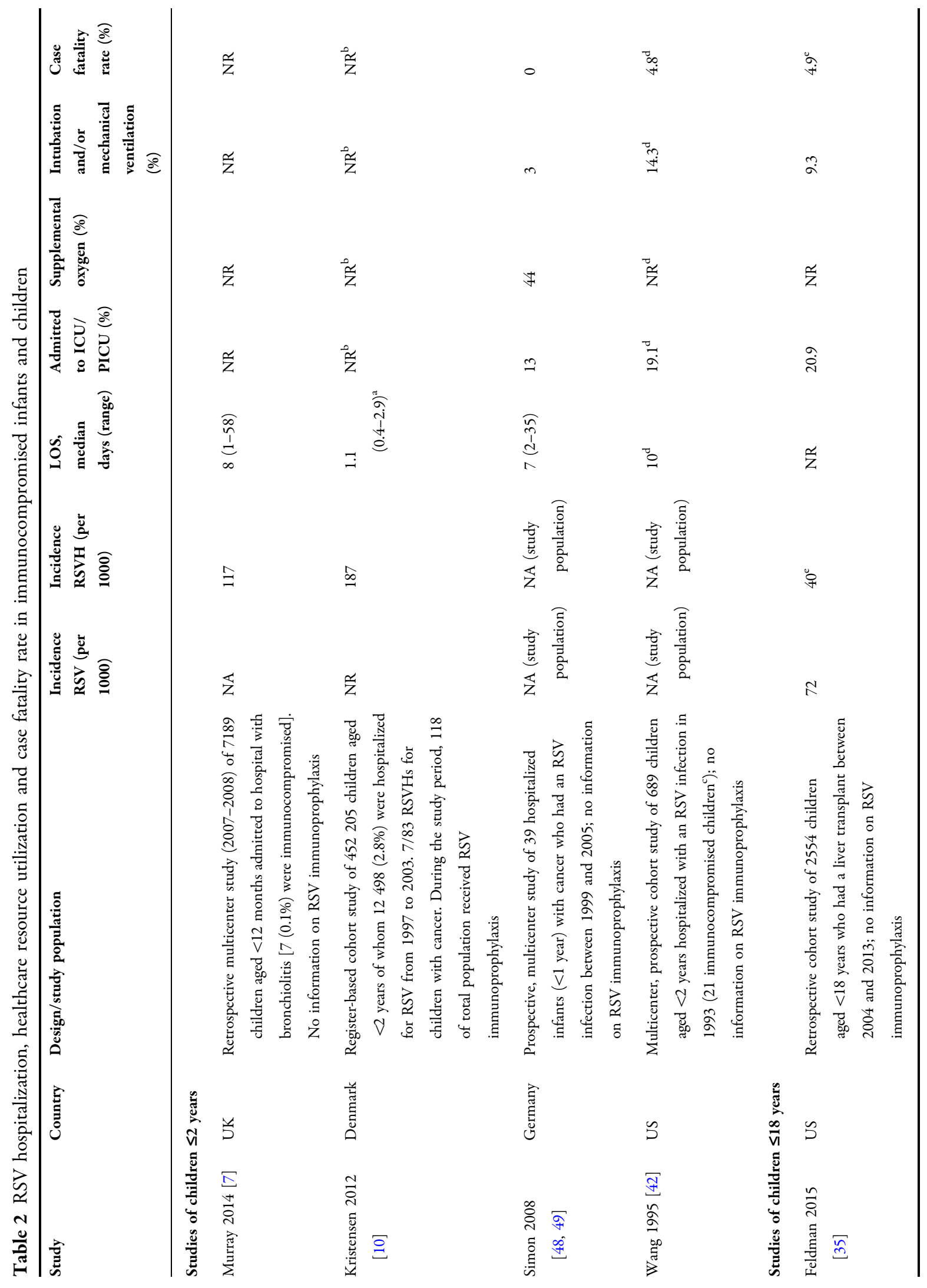




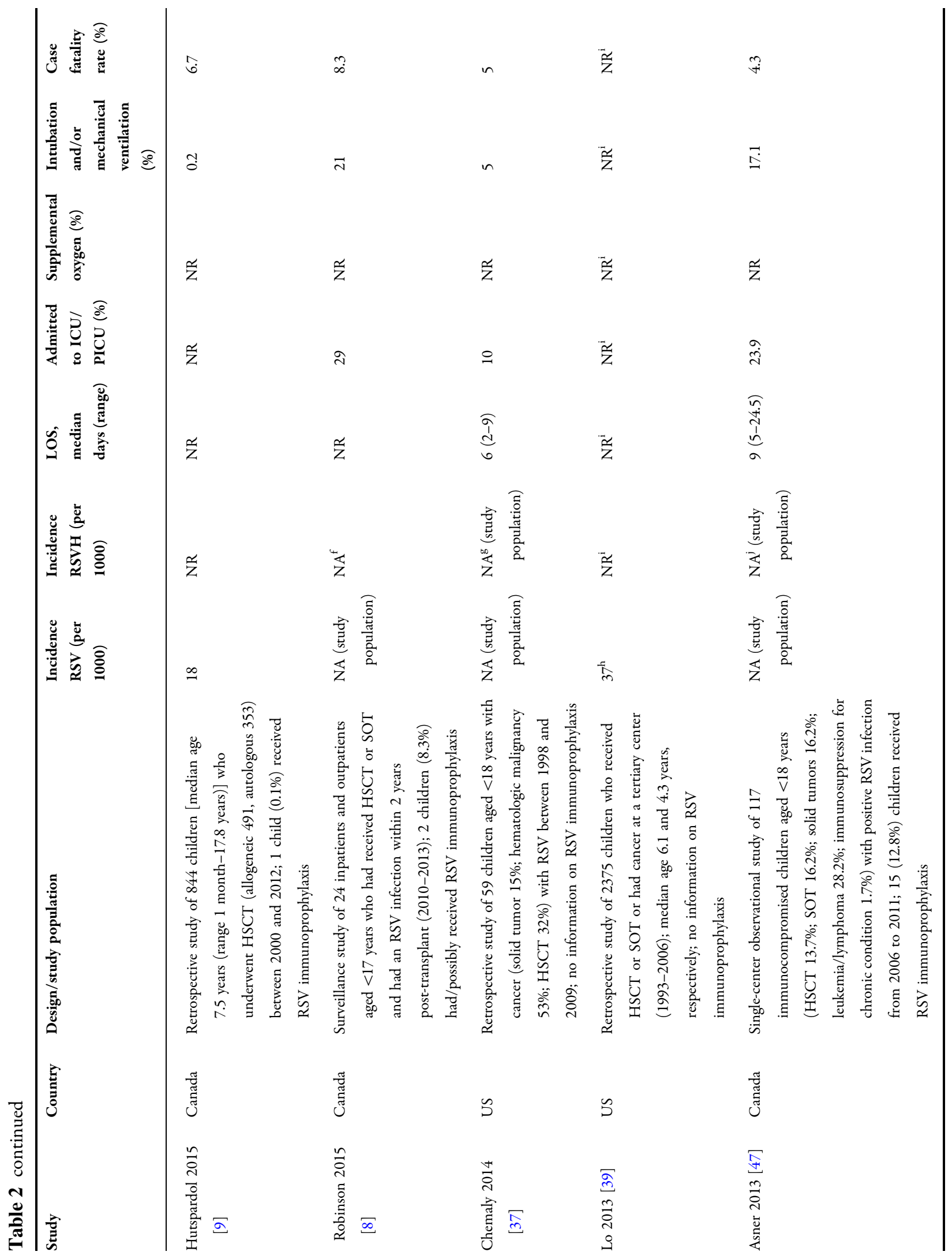




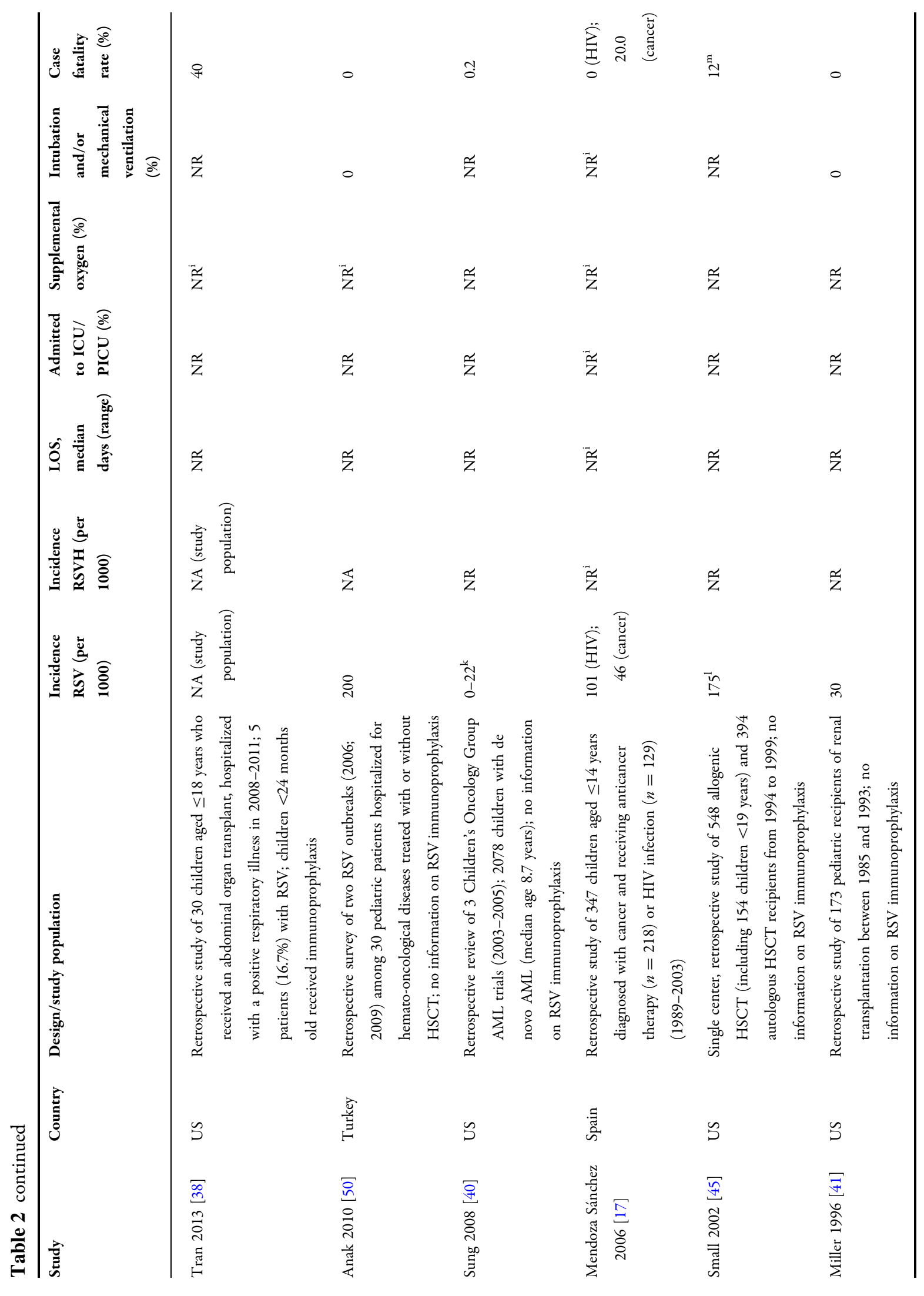




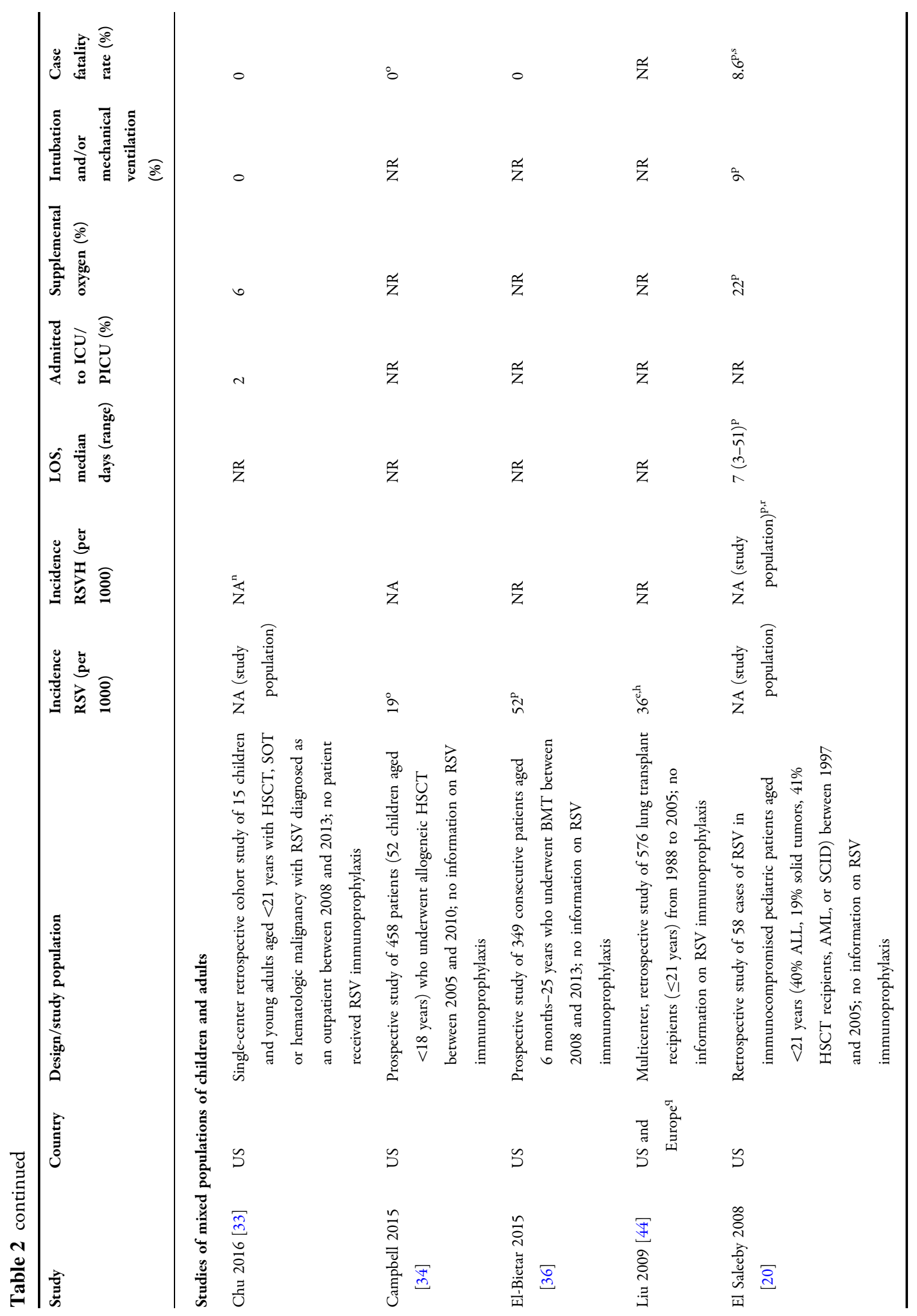




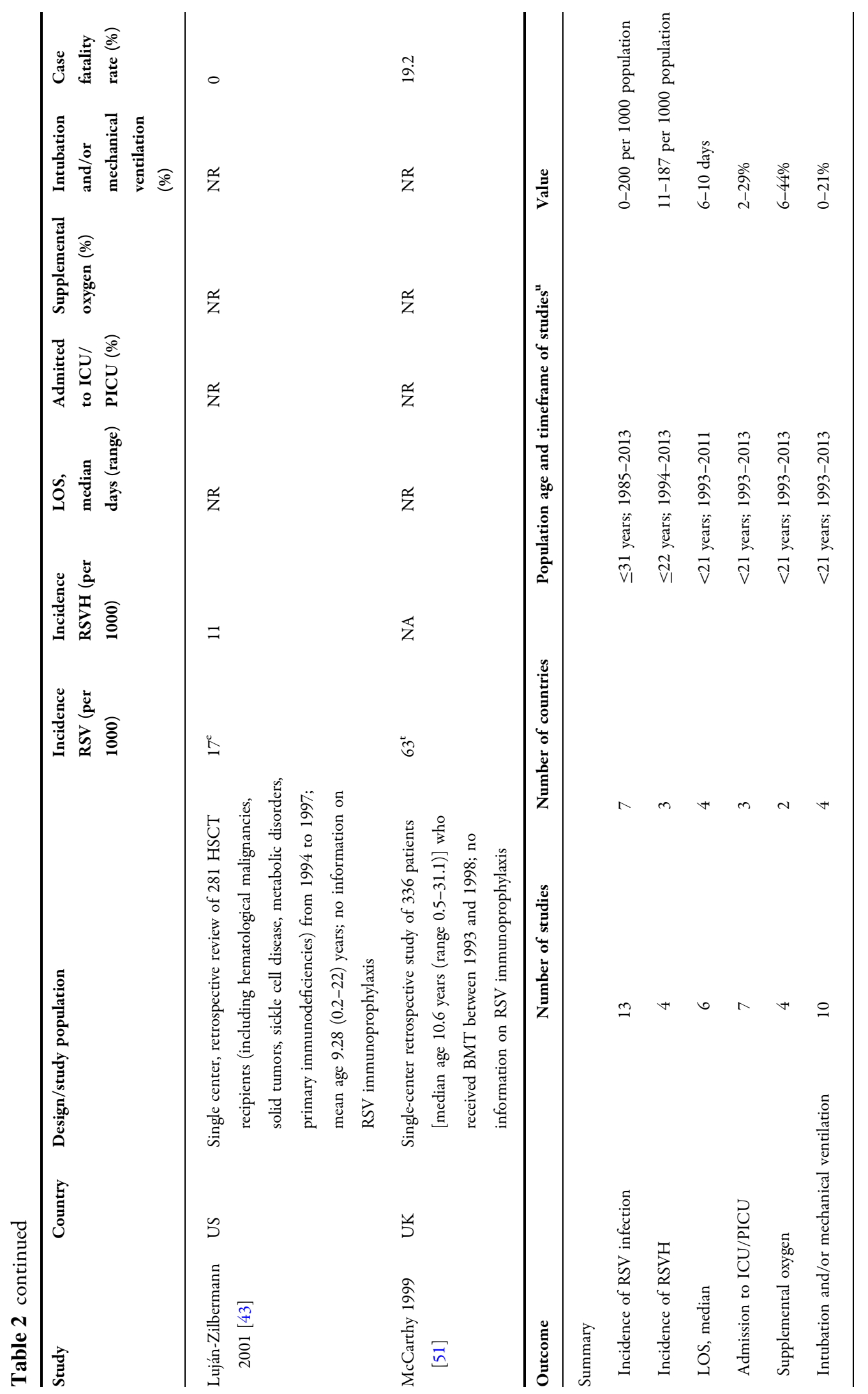




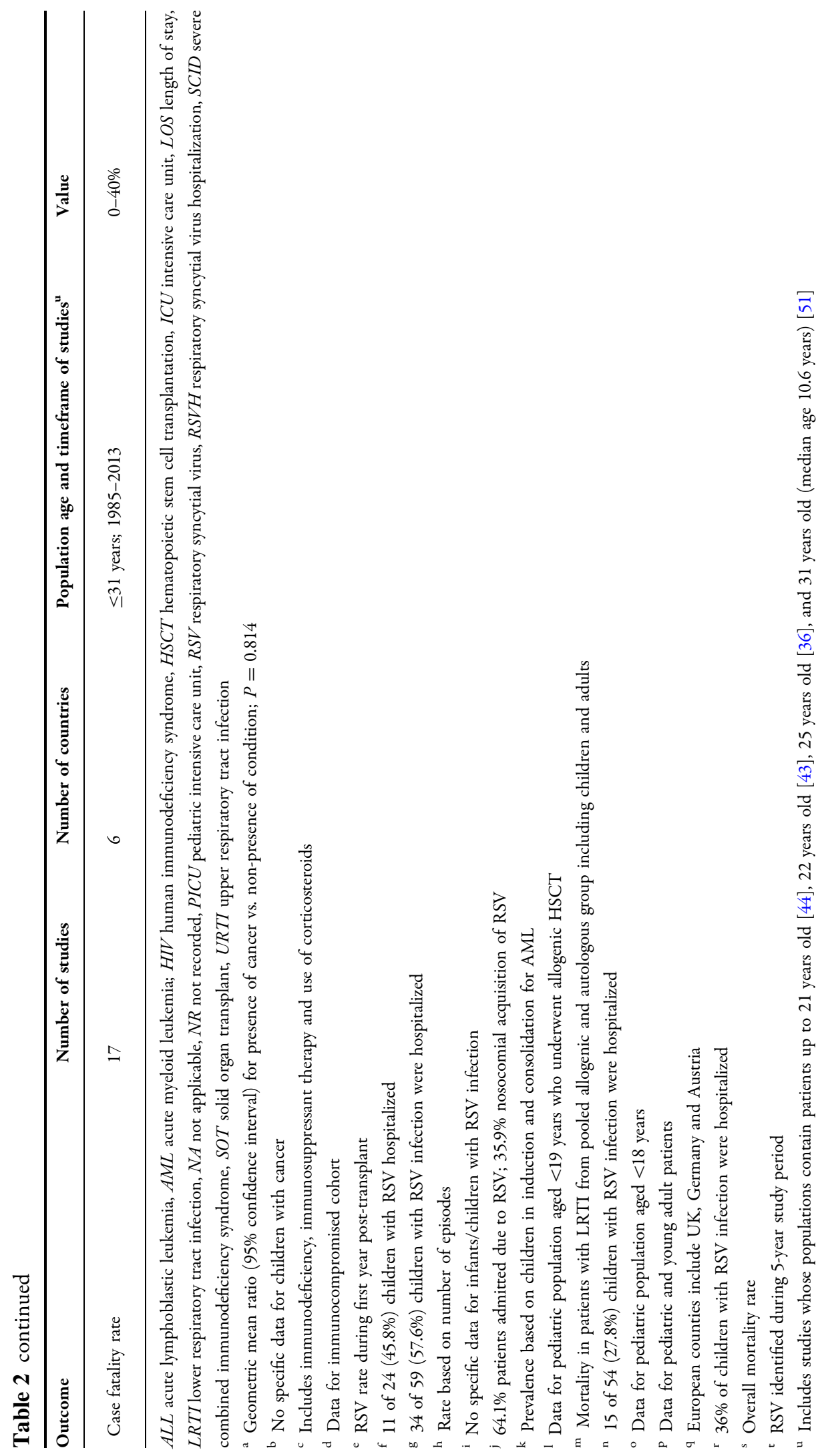




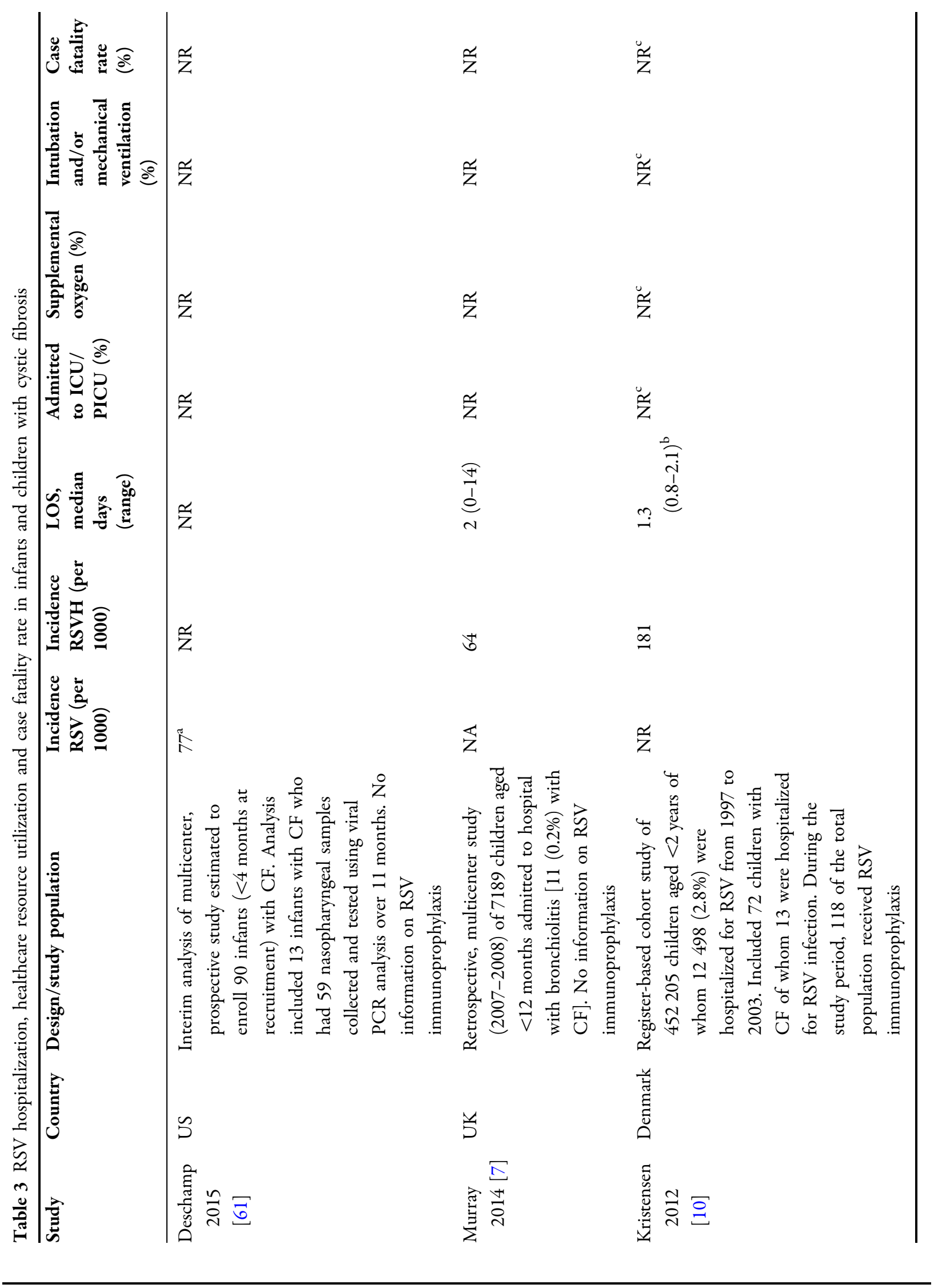




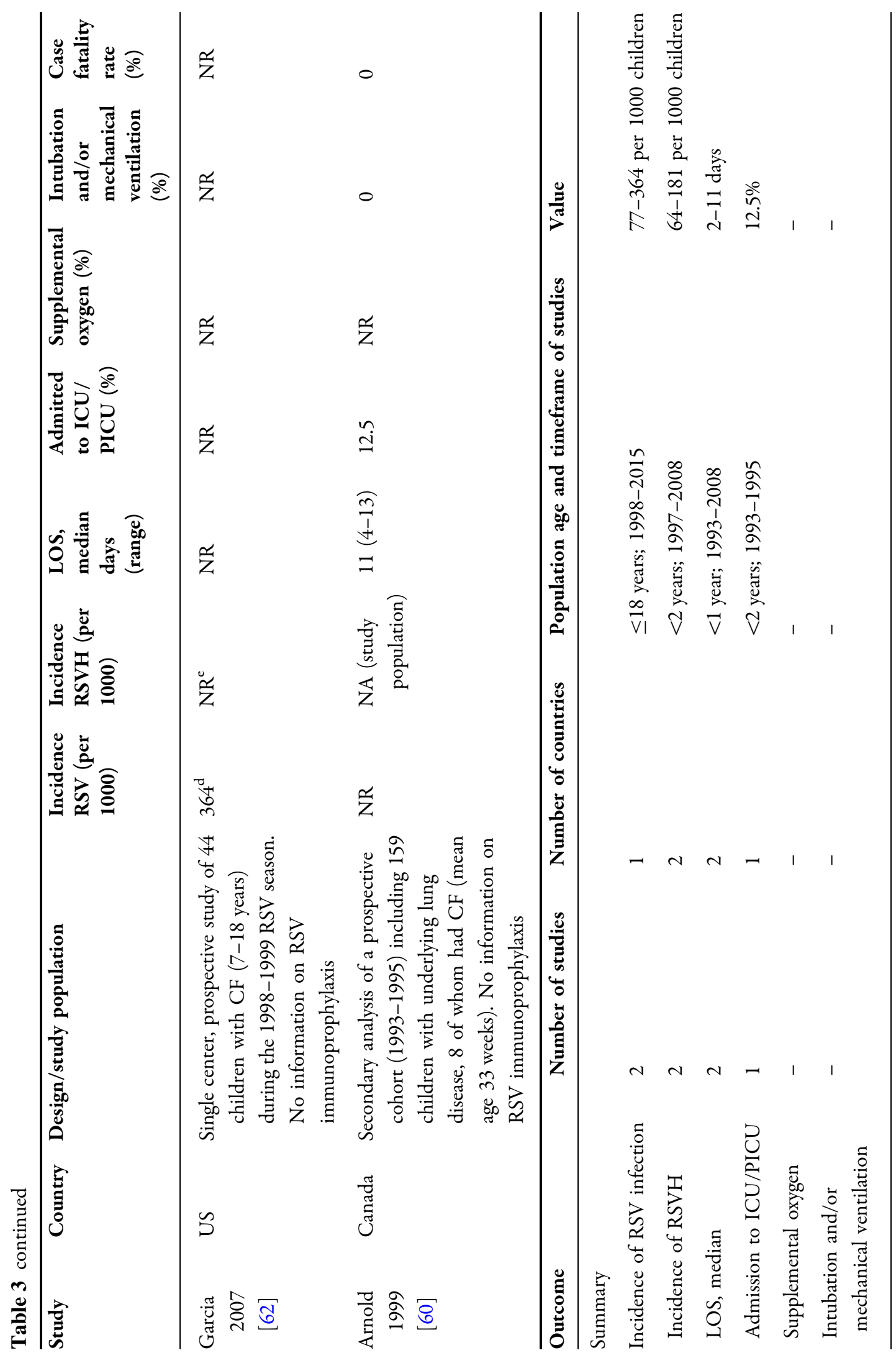




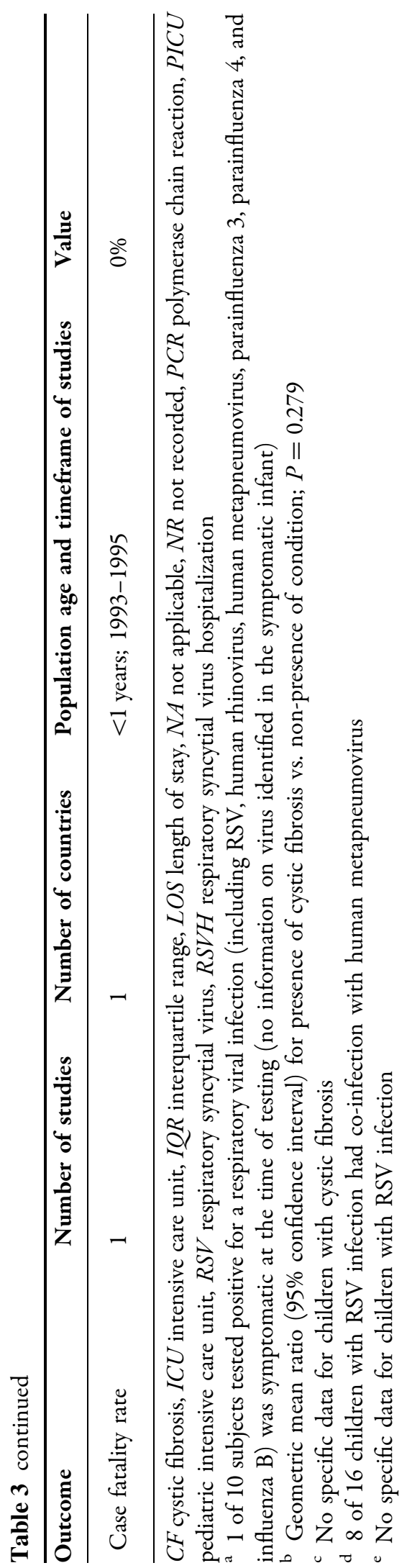

For patients undergoing HSCT or SOT, RSV infections typically occur within the first 2 years following transplant $[35,37]$. Increased disease severity has been associated with prolonged shedding of RSV and with higher viral loads maintained for longer periods [56].

Outbreaks of RSV have been reported to occur in cancer care outpatient departments where many pediatric patients with malignancy or those undergoing transplantation are managed $[33,50,57]$. In a retrospective study of all RSV infections in children with cancer from 1998 to 2009 at the MD Anderson Cancer Centre in Texas, Chemaly et al. [37] found that, whilst the majority of cases $(43 / 59 ; 73 \%)$ were community-acquired, over one-quarter (27\%) were nosocomial. Since many HSCT and SOT recipients and children with malignancies are frequently seen in clinics, this could explain in part the high rates of RSV infection reported among this patient group. Children mechanically ventilated for reasons other than the actual RSV infection have also been shown to face an increased risk of a severe course of disease [58]. These findings highlight the importance of infection control interventions in outpatient as well as inpatient hospital settings to reduce the spread of RSV infection.

Progression from a generally self-limiting upper respiratory tract infection (URTI) to a more severe LRTI has been shown to occur in $18-28 \%$ of RSV-infected, immune-compromised patients [20, 37, 59]. Kim et al. [59] in the US (Seattle, WA) retrospectively evaluated 181 HSCT recipients (median age 40 years; 6 children aged $<2$ years of age, 20 children aged 2 14 years) who presented with a RSV URTI. Twenty-four percent of patients $(43 / 181)$ progressed to RSV LRTI, although no progression was observed in the 6 children aged $<2$ years. In multivariable models, smoking history $(P=0.03 ;$ NB study included adult patients), receipt of high-dose total body irradiation $(P=0.03)$, and an absolute lymphocyte count $\leq 100 / \mathrm{mm}^{3}(P=0.002)$ at the time of URTI onset were significantly associated with disease progression [59]. In another retrospective study from the US (Memphis, TN) by El Saleeby et al. [20], 16 of 58 children (median age 4.3 years) with cancer (27.6\%) and a RSV URTI developed 
Table 4 Incidence rate ratios (IRR) for RSVH and geometric mean ratios for duration of RSVH in children with chronic conditions from the Danish RSV database [10]

\begin{tabular}{llll}
\hline Condition $^{\mathrm{a}}$ & RSV/ & IRR (95\% CI); & GMR for LOS $^{\mathrm{b}}$ \\
& Total (\%) & $P$ value & $(95 \% \mathrm{CI}) ; P$ value
\end{tabular}

\section{Congenital}

Malformations of respiratory system

Cleft lip and palate

Malformations of the larynx; trachea and bronchi

Malformation of the lungs

Other conditions associated with respiratory symptoms

Esophageal atresia

Neuromuscular disease

Encephalocele

Spina bifida and malformations of the spinal cord

Muscular dystrophy

Cerebral palsy
$50 / 855(6.4)$

$41 / 440(9.3)$

$7 / 51(13.7)$

$26 / 115(22.6)$

$2.8(1.6-4.9) ;<0.001$

$1.5(1.1-2.1) ; 0.009$

$2.2(1.0-4.8) ; 0.049$

$58 / 542(10.7)$

$1.5(1.1-2.1) ; 0.005$

$17 / 172(9.9)$

2.2 (1.3-3.6); 0.002

$13 / 82(15.9)$

93/905 (10.3)
2.5 (1.4-4.6); 0.003

$1.6(1.3-2.0) ;<0.001$
1.0 (0.8-1.3); NS

$1.1(0.8-1.5)$; NS

1.5 (0.7-3.2); NS

$1.8(1.1-3.1) ; 0.022$

$1.1(0.8-1.4)$; NS

$2.1(1.3-3.3) ; 0.003$

1.5 (0.9-2.4); NS

$1.3(1.1-1.6) ; 0.005$

Congenital diseases, chromosomal abnormalities, and others

Malformations of the urinary system ${ }^{c}$

Other chromosomal abnormalities

Malformations of the GI tract, liver, biliary system, pancreas, and abdominal wall

Congenital immunodeficiencies

Inborn errors of metabolism

\section{Acquired}

Interstitial lung disease

Gastroesophageal reflux

Epilepsy

Acquired heart disease

Liver disease

\begin{tabular}{lll} 
82/1232(6.7) & $1.5(1.2-1.9) ;<0.001$ & $1.0(0.8-1.2) ; \mathrm{NS}$ \\
$4 / 17(23.5)$ & $5.1(1.7-15.5) ; 0.004$ & $1.6(0.7-3.8) ; \mathrm{NS}$ \\
$94 / 1078(8.7)$ & $1.6(1.3-2.0) ;<0.001$ & $1.2(1.0-1.5) ; \mathrm{NS}$ \\
& & \\
26/122(21.3) & $2.4(1.6-3.5) ;<0.001$ & $1.2(0.9-1.8) ; \mathrm{NS}$ \\
29/276(10.5) & $2.4(1.6-3.5) ;<0.001$ & $1.1(0.8-1.5) ; \mathrm{NS}$ \\
& & \\
$3 / 11(27.3)$ & $6.5(1.7-23.9) ; 0.005$ & $1.3(0.4-4.1) ; \mathrm{NS}$ \\
$40 / 610(6.6)$ & $1.5(1.1-2.1) ; 0.019$ & $1.0(0.7-1.3) ; \mathrm{NS}$ \\
$75 / 713(10.5)$ & $2.6(2.1-3.4) ;<0.001$ & $1.6(1.3-2.0) ;<0.001$ \\
$53 / 427(12.4)$ & $2.0(1.5-2.7) ;<0.001$ & $1.1(0.8-1.4) ; \mathrm{NS}$ \\
$9 / 48(18.7)$ & $4.0(2.0-8.2) ;<0.001$ & $1.0(0.6-1.9) ; \mathrm{NS}$ \\
\hline
\end{tabular}

$C I$ confidence interval, GI gastrointestinal, GMR geometric mean ratio, LOS length of stay for RSVH, IRR incidence rate ratio, $N S$ not significant, $R S V$ respiratory syncytial virus, $R S V H$ respiratory syncytial virus hospitalization

${ }^{a}$ Excludes the following conditions all of which were identified as significant risk factors for RSVH: CLD, CHD (both out with remit of review), Down syndrome, cancer and cystic fibrosis (data presented in relevant sections of this paper and Tables 1, 2 and 3, respectively)

${ }^{b}$ Presence vs. no presence of condition

${ }^{c}$ Including vesicoureteral reflux and obstructive renal disease 
symptoms of LRTI. Age $\leq 2$ years (OR 9.8, 95\% CI 2.0-49.8) and profound lymphopenia (counts of $<100$ cells $/ \mathrm{mm}^{3}$ ) (OR $7.2,95 \%$ CI 1.2-44.0) at RSV diagnosis were independent predictors of the development of LRTI and of increased risk for RSV-related mortality in univariate analysis [20]. In their retrospective study undertaken in the US (Houston, TX), Chemaly et al. [37] observed that 11 of 59 (18.6\%) children (median age 5 years) with cancer progressed from RSV URTI to LRTI. In contrast to the studies by Kim et al. [59] and El Saleeby et al. [20], no significant risk factors for progression to LRTI were identified [37]. However, a trend of higher rate of RSV LRTI was observed for male sex (OR 2.6, 95\% CI 0.9-7.6; $P=0.09$ ) and children with lymphocytopenia (counts of $<200$ cells/mL; OR 3.0, 95\% CI 0.9-10.1; $P=0.085$ ), though they did not study profound lymphopenia [37].

For children not already hospitalized due to their underlying condition or its treatment, RSV infections were severe enough to warrant admission to hospital in $28-58 \%$ of cases $[8,20,33,37,47]$. Four studies were identified describing RSVH rates in immunocompromised children [7, 10, 35, 43]. Feldman et al. [35] in the US undertook a retrospective cohort study of 2554 children aged $<18$ years who had liver transplants between 2004 and 2013 and reported an RSVH rate in the first year post-transplant of 40 per 1000 children. Another US study, by Luján-Zilbermann et al. [43], retrospectively reviewed 281 patients (mean age 9.28 years) receiving HSCT from 1994 to 1997 and found a rate of RSVH of 11 per 1000; this study included patients with hematological malignancies, solid tumors, sickle cell disease, metabolic disorders, and primary immunodeficiencies. A higher rate of RSVH of 117 per 1000 was reported by Murray et al. [7] among infants ( $<1$ year) with immunodeficiencies. The highest rate of RSVH was reported in the Danish national study of 187 per 1000 in children with cancer $<2$ years old [10].

Studies have shown that immunocompromised children spend an average of 6-10 days in hospital for RSV infections, with up to $29 \%$ requiring admission to the ICU and up to $21 \%$ intubation and/or mechanical intervention
[7-9, 20, 33, 35, 37, 42, 47-50]. Asner et al. [47] from Canada, in a single-center observational study of 117 immunocompromised children aged $<18$ years presenting with an LRTI or URTI, identified the following independent predictors for a prolonged hospital stay: nosocomial RSV infection $(P<0.001)$ and the presence of high-risk underlying comorbidities (HSCT and SOT recipients, and congenital immunodeficiencies; $P=0.008$ ).

\section{Cystic Fibrosis}

Cystic fibrosis has been found to be a significant risk factor for severe RSV infection [7, 10, 60-63] (Table 3). In the population-based, cohort study by Murray et al. [7], admission rates for RSV LRTI during the first year of life were found to be significantly higher among infants with cystic fibrosis (64 per 1000 infants, 95\% CI 32.1-115.1) compared with otherwise healthy infants born at term (22 per 1000 infants, 95\% CI 21.8-22.9; RR 2.5, 95\% CI 1.4-4.4). In contrast to the previous study, a considerably higher rate of RSVH of 181 per 1000 in children ( $<2$ years) with cystic fibrosis was reported in the Danish national RSV cohort [10]. Cystic fibrosis was a significant risk factor for RSVH in this study (IRR 4.3, 95\% CI 2.4-7.7; $P<0.001$ [10].

In a subgroup analysis of the Canadian PICNIC RSV database, the morbidity of RSV infection in children $(n=68)$ with various causes of underlying lung disease (including cystic fibrosis, recurrent aspiration pneumonitis, pulmonary malformation, neurogenic disorders, and tracheoesophageal fistula) was found to be similar to those with BPD $(n=91)$ [60]. Median hospitalization varied from 5 to 13 days and was similar between groups. The proportions of children admitted to ICU and mechanically ventilated were also similar among the different groups [60]. Across studies, the median LOS in hospital for RSV infection for infants $(<1$ year) with cystic fibrosis was $2-11$ days $[7,60]$.

Importantly, Hiatt et al. [63] observed that the decline in lung function caused by a RSV LRTI among children ( $<2$ years) with cystic fibrosis can persist for several months (mean 3.2 months) after resolution of the infection. 
This finding is of great interest, and might be consistent with recently published findings from a large cohort study from the US including 12,702 children with cystic fibrosis, which reported that RSV activity was significantly associated with an increased risk of pulmonary exacerbations (RR 1.05, 95\% CI 1.02-1.07, for a $10 \%$ increase in the proportion of surveillance tests positive for RSV; $P<0.001$ ) [64]. Experimental reports have also implicated RSV in facilitating lung disease in cystic fibrosis caused by Pseudomonas aeruginosa $[65,66]$. RSV infection has been shown to increase adherence of $P$. aeruginosa to epithelial monolayers in vitro by up to 16-fold [65], and to increase colonization in lung homogenates by 2000 times and impact lung function changes in mice [66].

\section{Neurological and Neuromuscular Disorders, Congenital Malformations, and Other Chronic Conditions}

There are a number of other diseases and conditions, both congenital and acquired, that have been reported to increase the vulnerability of infants and children to severe RSV infection $[7,10,11,16,18,19,21,67-69]$. The national, population-based study conducted in Denmark analyzed chronic conditions in groups based on anatomy and physiology and some single disease entities amongst a study population of 452 205 children aged 0-23 months [10]. Of the 12498 children hospitalized for RSV infection, $930(8.8 \%)$ had a diagnosis of chronic disease; these children were older than otherwise healthy children at the time of admission (median, 7.9 vs. 6.2 months, respectively; $P=0.001$ ). Adjusted incidence rate ratios for RSVH were 2.2 (95\% CI 2.0-2.4) for children with any congenital condition and 2.3 (95\% CI 1.9-2.6) for children with an acquired chronic condition. Cleft lip and palate, malformations of the respiratory system and esophagus, neuromuscular disease, malformations of the urinary system (including vesicoureteral reflux and obstructive renal disease), other intra-abdominal malformations (including malformations of the abdominal wall), chromosomal abnormalities other than Down syndrome, congenital immunodeficiencies, and inborn errors of metabolism were each independently associated with an increased risk of RSVH (Table 4). Among acquired conditions, the adjusted rates of RSVH were sixfold higher in patients with interstitial lung disease, fourfold higher in those with liver disease, and at least twofold higher in those with epilepsy, acquired heart disease, and cancer, than in those without the said condition. The duration of RSVH was also significantly increased in infants and children with malformations of the esophagus, some neuromuscular diseases, and epilepsy [10].

Another large, retrospective study by Zachariah et al. [16] identified 77 RSVHs in 3417 children born with major congenital malformations between 1997 and 2004 in Colorado, US (incidence 22 per 1000). When compared to those without malformations, children with spina bifida without anencephaly (RR 2.7, 95\% CI 2.0-3.7), agenesis, hypoplasia, or dysplasia of the lung (RR 1.4, 95\% CI 1.0-2.0), cleft palate alone (RR 1.4, 95\% CI 1.0-2.0), and biliary atresia (RR 3.4, 95\% CI 2.2-5.4) had statistically higher risks of being hospitalized with RSV LRTI in the first 2 years of life. Microcephaly, anomalies of the diaphragm, and choanal atresia were not associated with an elevated risk, whereas hypertrophic pyloric stenosis and cleft lip were associated with a lower risk of being hospitalized with RSV LRTI [16].

The study by Murray et al. [7] observed higher rates of RSVH in infants $<1$ year with cerebral palsy (107 per 1000 infants, 95\% CI 61.4-174.4; RR 2.4, 95\% CI 1.5-4.0) and nervous system congenital abnormalities (86 per 1000 infants, 95\% CI 61.9-116.1; RR 1.7, 95\% CI 1.3-2.4) than otherwise healthy infants born at term (22 per 1000 infants, 95\% CI 21.8-22.9). A neurological disorder [defined as the presence of one or more of the following diagnoses: Intracranial hemorrhage grade III or IV (periventricular hemorrhage), cystic periventricular leukomalacia, cerebral infarction, hydrocephalus or other symptomatic neurological conditions] has also been found to be an independent risk factor for RSVH in a multivariate analysis of 1158 children born preterm at 29-35 weeks' gestational age in Germany and Austria (OR 3.6, 95\% CI 1.3-9.9; $P=0.01$ ) [67]. 
Findings from a prospective, multicenter study by Wilkesmann et al. [11], covering 6 consecutive RSV seasons (1999-2005), illustrated that children with neuromuscular impairment have more severe RSV LRTI, since they have a longer median LOS in hospital ( 11 days vs. 7 days; $P<0.001)$ and higher requirement for mechanical ventilation (9.6\% vs. $1.9 \% ; P<0.001$ ), compared to children without neuromuscular impairment. Furthermore, multivariate logistic regression confirmed that neuromuscular impairment was independently associated with PICU admission (OR 4.94, 95\% CI 2.7-8.9; $P<0.001)$ and mechanical ventilation (OR 3.9, 95\% CI 1.3-10.2; $P=0.017$ ) [11]. These findings were confirmed by a second retrospective study by Purcell et al. [69] in the US who found that infants and young children with neurologic disease $(n=38)$ had significantly longer LOS in hospital $(5.4 \pm 3.3$ vs. $3.9 \pm 2.2$ days; $P<0.05)$, admittance to PICU $(23.7 \%$ vs. $3.2 \%$; $P<0.001)$, and requirement for mechanical ventilation $(18.4 \%$ vs. $1.5 \%$; $P<0.001)$ for RSV LRTI, than children without risk factors $(n=2287)$.

Data are available for a few other diseases and conditions associated with increased morbidity from RSV infection. Data from a prospective, multicenter study conducted in Spain showed that children ( $<5$ years) with inborn errors of metabolism required significantly more frequent admission to PICU (OR 6.7, 95\% CI 1.2-38.0; $P<0.05)$ and requirement for mechanical ventilation (OR 12.3, 95\% CI 2.1-71.5) for RSV infection than previously healthy children [21, 70]. Pockett et al. [19], using nationwide data for England from 2001 to 2008 , found that children (mean age 1 year) with chronic diseases including insulin-dependent diabetes mellitus, epilepsy, cancer, or cystic fibrosis, hospitalized with RSV infection had greater LOS [mean 10.1 days, standard deviation (SD) 22.5] than otherwise healthy children (mean age 0.1 years) hospitalized with RSV infection (mean 1.9 days, SD 3.2).

\section{Incidence of RSVH Over Time in Children Affected by Underlying Comorbidities}

A recently published study from the US has reported that RSVH rates have not declined in
Down syndrome without CHD, CAA, and a number of other conditions (cystic fibrosis with pulmonary manifestations, neuromuscular disease, HIV, immunodeficiency, and other genetic metabolic musculoskeletal conditions) [18]. This 15-year (1997-2012) historical cohort study, using data from the nationwide Kids' Inpatient Database, found that RSVH rates increased by $7.6 \%$ for Down syndrome without CHD $(P=0.09)$, by $4.3 \%$ for CAA $(P=0.41)$, and by $9.3 \%$ for other high risk conditions $(P=0.62)[18]$.

\section{Case Fatality Rates}

There are relatively few studies that have reported RSV-related mortality in infants and children with underlying medical conditions or chronic diseases. Infections are well known to make an important contribution to mortality in children with cancer [71, 72], and RSV-attributable case fatality rates have been reported as high as $19 \%$ in children undergoing bone marrow transplant, primarily for hematological malignancies [51]. Case fatality rates as high as $40 \%$ have also been reported in SOT recipients [38]. The majority (13/ 18) of studies, however, report rates of RSV-related mortality in immunocompromised children and young adults at below 10\% (includes seven studies with no RSV-attributable mortality) $[8,9,17,33-38,40-43,45,47,49-51]$. In the study by Wilkesmann et al. [11] RSV-attributable mortality was significantly higher in the neuromuscular impairment group than those without the condition ( $5.5 \%$ vs. $0.2 \%$, respectively; $P<0.001$ ). Individual studies in Down syndrome and cystic fibrosis provide few insights into RSV-related mortality in these patient groups.

Two studies were identified that specifically investigated RSV-related mortality in children, including those with underlying medical conditions [73, 74]. Thorburn et al. [73] in the UK undertook a study of 406 children (median age 5.1 months) admitted to the PICU over an 8-year period (1999-2007) and found 18 deaths (4.4\%) directly related to RSV infections. All of these children had pre-existing medical conditions: chromosomal abnormalities (29\%); cardiac lesions (27\%); neuromuscular (15\%); CLD (12\%); 
large airway abnormality (9\%); and immunodeficiency (9\%). Predisposing risk factors for death were pre-existing disease (RR 2.4, 95\% CI 2.0-2.8), cardiac anomaly (RR 3.0, 95\% CI 2.2-4.1), and nosocomial/hospital-acquired RSV infection (RR 2.9, 95\% CI 1.3-6.6) [73]. A more recent analysis of RSV mortality rates in hospitalized infants and children aged $<2$ years was undertaken in the US using the Kids' Inpatient Database and the Pediatric Health Information System [74]. Both datasets indicated that RSVH-associated mortality was uncommon, occurring in 3-4 per 10000 admissions, and had decreased over the last 20 years. Of these deaths, $20-26 \%$ had neuromuscular conditions and $13-19 \%$ had congenital or genetic conditions. Nearly $40 \%$ of the deaths in both datasets occurred in medically fragile infants and children with $\geq 2$ complex chronic conditions [74].

\section{Limitations}

The rarity of the vast majority of the conditions, diseases and disorders covered in this review inevitably results in studies with often small populations of particular interest, data captured retrospectively over many years using various methodologies, and different diagnoses reported together sometimes in combination. This is perhaps most evident when considering immunocompromised children, where HSCT and SOT recipients with various underlying malignancies and treatment regimens were often studied in concert. Also, when looking at underlying conditions that have no direct consequence on the cardio-respiratory system, such as for example, urinary tract malformation, it is not possible to relate the increased incidence of RSV infection to the underlying condition (which seems unlikely) or to the risks and side effects of the medical management (i.e. recurrent hospital visits). Accurate information on RSV-related mortality, in particular, is difficult to obtain clear information on when analyzed retrospectively in the context of significant, life threatening comorbidities, such as cancer. Variation in hospitalization practices both for the conditions of interest and for RSV infections and changes in RSV surveillance over time and between countries (including level and methodology of testing and specimen used) will also have influenced the results and conclusions drawn.

\footnotetext{
Key statements/findings

Level of evidence ${ }^{a}$

A number of conditions, diseases, and disorders are associated with an increased risk of severe RSV disease and related morbidity and mortality

\section{Down syndrome}

Down syndrome is a significant risk factor for RSVH in early ( $<3$ years) childhood (rate ratio ${ }^{b}: 2.5-12.6$ ), even when excluding co-existing risk factors for severe RSV disease, such as CHD and prematurity (rate ratio ${ }^{\mathrm{b}}$ : 3.5-10.5) [moderate $\mathrm{SOE}^{\mathrm{c}}$ ]

RSVH rate of 70-195 per 1000 children [moderate $\mathrm{SOE}^{\mathrm{c}}$ ]

Average of 3-10 days hospitalization [moderate $\mathrm{SOE}^{\mathrm{c}}$ ]

Irrespective of other risk factors, increased severity of disease, longer duration of hospital stay, and greater risk of respiratory support, including intubation and/or mechanical ventilation, versus otherwise healthy children [moderate/low $\mathrm{SOE}^{\mathrm{c}}$ ]

Level 1 studies: $n=1$; Level 2 studies: $n=8$; Level 3 studies: $n=1^{\mathrm{d}}$

Risk of bias ${ }^{\mathrm{e}}$ : very low
} 
continued

Key statements/findings

Level of evidence ${ }^{a}$

Im munocompromised children (including HSCT/BMT recipients, SOT recipients, cancer patients on chemotherapy, children with SCID/DiGeorge syndrome, and those with HIV)

RSVH rate of 11-187 per 1000 children and young adults [low $\mathrm{SOE}^{\mathrm{c}}$ ]

Average of 6-10 days hospitalization with $\leq 29 \%$ admitted to ICU and $\leq 21 \%$ requiring intubation and/or mechanical intervention [low $\mathrm{SOE}^{\mathrm{c}}$ ]

Independent predictors of prolonged hospital stay: nosocomial RSV infection $(P<0.001)$ and presence of HSCT, SOT or congenital immunodeficiencies $(P=0.008)\left[\right.$ low $\left.\mathrm{SOE}^{\mathrm{c}}\right]$

\section{Cystic fibrosis}

Cystic fibrosis is a significant risk factor for RSVH in early ( $<2$ years) childhood (rate ratio ${ }^{\mathrm{b}}: 2.5-4.3$ ) [low $\left.\mathrm{SOE}^{\mathrm{c}}\right]$

RSVH rate of 64-181 per 1000 children [low $\mathrm{SOE}^{\mathrm{c}}$ ]

Average of 2-11 days hospitalization [low $\mathrm{SOE}^{\mathrm{c}}$ ]

Morbidity (LOS, ICU, mechanical ventilation) of RSV in children with various forms of underlying lung disease (including cystic fibrosis) similar to those with CLD [low $\left.\mathrm{SOE}^{\mathrm{c}}\right]$

\section{Neurological and neuromuscular disorders, congenital malformations, and other chronic conditions}

Neurological and neuromuscular conditions (including spina bifida, cerebral palsy, and muscular dystrophy ${ }^{\mathrm{i}}$ ) are associated with a significantly $(P<0.05)$ increased risk of RSVH and increased morbidity [low SOE ${ }^{c}$ ]

A number of other congenital malformations and chronic conditions ${ }^{\mathrm{k}}$ are also associated with a significantly $(P<0.05)$ increased risk of RSVH [low SOE]

\section{RSV-attributable mortality}

Immunocompromised children, case fatality rates: $0-40 \%$ (7/18 studies with 0\%) $\left[\right.$ low $\left.\mathrm{SOE}^{\mathrm{c}}\right]$

Underlying medical conditions, case fatality rates: $<1 \%$, with pre-existing disease (RR 2.4, 95\% CI 2.0-2.8) a significant risk factor for mortality [low $\left.\mathrm{SOE}^{\mathrm{c}}\right]$
Level 1 studies: $n=0$

Level 2 studies: $n=8$

Level 3 studies: $n=1^{\mathrm{j}}$

Risk of bias ${ }^{\mathrm{e}}$ : very low
Level 1 studies: $n=1$

Level 2 studies: $n=6$

Level 3/4 studies: $n=17$

Risk of bias ${ }^{\mathrm{e}}$ : very low ${ }^{1}$
Level 1 studies: $n=1$

Level 2 studies: $n=5$

Level $3 / 4$ studies: $n=21^{\mathrm{f}}$

Risk of bias ${ }^{\mathrm{e}}:$ low $^{\mathrm{g}}$

Level 1 studies: $n=0$ Level 2 studies: $n=5$ Level 3 studies: $n=1^{\mathrm{h}}$

Risk of bias ${ }^{\mathrm{e}}$ : very low 
continued

Key statements/findings

Level of evidence ${ }^{a}$

\section{Key areas for research}

Where feasible, larger, prospective, well-designed studies are needed to more fully define the risk and outcomes of RSV infection in these populations

More data are needed on fatality rates in children with underlying medical conditions or chronic diseases to determine how much is directly attributable to RSV and the true burden of disease

$B M T$ bone marrow transplant, $C H D$ congenital heart disease, $C I$ confidence interval, $H R$ hazard ratio, HSCT hematopoietic stem cell transplant, $I C U$ intensive care unit, $L O S$ length of stay, $R R$ relative risk, $R S V$ respiratory syncytial virus, $R S V H$ respiratory syncytial virus hospitalization, $S C I D$ severe combined immunodeficiency, SOT solid organ transplant, $H I V$ human immunodeficiency virus

${ }^{a}$ Level 1: Local and current random sample surveys (or censuses); Level 2: Systematic review of surveys that allow matching to local circumstances; Level 3: Local non-random sample; Level 4: case series [24, 25]. When grading the evidence, in general, we considered prospective, cohort studies as Level 1; prospective, case-control studies or large (e.g. national or multinational), well-designed, retrospective studies as Level 2; well-designed, retrospective studies as Level 3; and small/ methodological weak retrospective studies and case series as Level 4

${ }^{b}$ Includes odds ratio, relative risk, incident rate ratio, and hazard ratio

c SOE (strength of evidence): high = supported by Level 1 evidence; Moderate: supported by limited Level 1 and/or Level 2 evidence; Low: supported by limited Level 2 and/or Level 3 evidence

d Six of the 10 studies specifically investigated children with Down syndrome (one Level 1 study [30] and five Level 2 studies $[15,22,27,29,31]$

e Average RTI Item Bank Score [26], where 7-9 = low risk of bias and 10-12= very low risk of bias

f 23 of the 27 studies specifically investigated immunocompromised children (one Level 1 study in HSCT recipients [34]; two Level 2 studies in SOT recipients [44] and in a mixed population of immunocompromised children (HSCT, SOT and chemotherapy recipients, and those on long-term immunosuppression) [47]; 15 Level 3 studies in HSCT/BMT $[9,36,43,45,51,52]$, chemotherapy [49], SOT [35, 38], and mixed populations of immunocompromised children (including chemotherapy, SOT, HSCT/BMT, severe combined immunodeficiency, and HIV) [17, 20, 33, 37, 39, 40]; and five Level 4 studies in SOT [41, 46], HSCT [54], chemotherapy recipients [55], and chemotherapy and BMT recipients [50])

${ }^{g}$ Six studies could not be scored due to insufficient information provided or case reports

h Three of the six studies specifically investigated children with cystic fibrosis (all Level 2 studies [61-63])

i Also including: Intracranial hemorrhage grade III or IV (periventricular hemorrhage); cystic periventricular leukomalacia; cerebral infarction; encephalocele; hydrocephalus; malformations of the spinal cord; epilepsy; and other symptomatic neurological conditions

${ }^{j}$ Eight studies included neurological/neuromuscular conditions (seven Level 2 and one Level 3) [7, 10, 11, 16, 67-69], one of which (Level 2 study) was specifically focused on children with neuromuscular impairment [11]

${ }^{k}$ Including [10, 16, 19, 21]: cleft lip and palate; malformations of the larynx, trachea and bronchi; malformation of the lungs; esophageal atresia; malformations of the urinary system; other chromosomal abnormalities; malformations of the GI tract, liver, biliary system, pancreas, and abdominal wall; congenital immunodeficiencies, inborn errors of metabolism; interstitial lung disease; gastroesophageal reflux; acquired heart disease; liver disease; and insulin dependent diabetes mellitus

${ }^{1}$ Three studies could not be scored due to insufficient information provided or case reports 


\section{CONCLUSIONS}

Respiratory syncytial virus is a major public health concern. Findings from this systematic review provide further evidence that RSV infection may be severe in children with a variety of underlying medical conditions or chronic diseases, leading to hospitalization, prolonged LOS, need for admission to ICU and mechanical ventilation, and even death. Certain high-risk groups, including children with Down syndrome and children immunocompromised through the administration of anticancer chemotherapy, and especially HSCT and SOT recipients, and those with neurological disorders, have increased RSV-related morbidity when hospitalized than otherwise healthy children with RSV infection.

\section{ACKNOWLEDGEMENTS}

Sponsorship and article processing charges for this study were funded by AbbVie. Dr. Joanne Smith, Julie Blake (Reviewers 1 and 2) and Dr. Barry Rodgers-Gray (Reviewer 3), from Strategen Limited, undertook the systematic review following the protocol approved by the authors. AbbVie provided funding to Strategen to undertake the systematic review. All named authors meet the International Committee of Medical Journal Editors (ICMJE) criteria for authorship for this manuscript, take responsibility for the integrity of the work as a whole, and have given final approval to the version to be published. Editorial assistance in the preparation of this manuscript was provided by Julie Blake and Barry Rodgers-Gray. Julie Blake and Barry Rodgers-Gray developed a first draft of the manuscript, based on the results of the systematic review and input/approval from all authors, which was initially edited by Xavier Carbonell-Estrany and Paolo Manzoni and then circulated among the other authors for input, further edits and subsequent approval. Support for this editorial assistance was funded by AbbVie. AbbVie had the opportunity to review and comment on the completed manuscript but final editorial control rested fully with the authors.

Disclosures. The institute of Louis Bont received money for investigator initiated studies by MeMed, AstraZeneca, AbbVie, and Janssen. The institute of Louis Bont received money for consultancy by AstraZeneca, AbbVie, MedImmune, Janssen, Gilead and Novavax. Paul Checchia has acted as an expert advisor and speaker for AbbVie and has received honoraria in this regard. He has also received research grant funding from AstraZeneca. Brigitte Fauroux has received compensation as a neonatology board member from AbbVie. Josep Figueras-Aloy has acted as an expert advisor and speaker for AbbVie and has received honoraria in this regard. Paolo Manzoni has acted as a speaker for AbbVie and as an expert advisor for AbbVie, TEVA, Medimmune, AstraZeneca, Janssen, and has received honoraria in this regard. Bosco Paes has received research funding from AbbVie Corporation and compensation as an advisor or lecturer from AbbVie and MedImmune. Eric Simões has received grant funding to his institution from Medimmune, Glaxo Smith Kline Inc, and received consultancy fees to the institution, from AbbVie. Xavier Carbonell-Estrany has acted as an expert advisor and speaker for AbbVie and has received honoraria in this regard.

Compliance with Ethics Guidelines. The analysis in this article is based on previously published studies and does not involve any new studies of human or animal subjects performed by any of the authors.

Open Access. This article is distributed under the terms of the Creative Commons Attribution-NonCommercial 4.0 International License (http://creativecommons.org/licenses/ by-nc/4.0/), which permits any noncommercial use, distribution, and reproduction in any medium, provided you give appropriate credit to the original author(s) and the source, provide a link to the Creative Commons license, and indicate if changes were made. 


\section{REFERENCES}

1. Nair H, Nokes DJ, Gessner BD, Dherani M, Madhi SA, Singleton RJ, et al. Global burden of acute lower respiratory infections due to respiratory syncytial virus in young children: a systematic review and meta-analysis. Lancet. 2010;375:1545-55.

2. Bont L, Checchia P, Fauroux B, Figueras-Aloy J, Manzoni P, Paes B, et al. Defining the epidemiology and burden of severe respiratory syncytial virus infection among infants and children in western countries. Infect Dis Ther. 2016;5:271-98.

3. Glezen WP, Taber LH, Frank AL, Kasel JA. Risk of primary infection and reinfection with respiratory syncytial virus. Am J Dis Child. 1986;140:543-6.

4. Figueras-Aloy J, Manzoni P, Paes B, Simões EAF, Bont L, Checchia PA, et al. Defining the risk and associated morbidity and mortality of severe respiratory syncytial virus infection among preterm infants without chronic lung disease or congenital heart disease. Infect Dis Ther. 2016;54:417-52.

5. Paes B, Fauroux B, Figueras-Aloy J, Bont L, Checchia PA, Simões EAF, et al. Defining the risk and associated morbidity and mortality of severe respiratory syncytial virus infection among infants with chronic lung disease. Infect Dis Ther. 2016;5:453-71.

6. Checchia PA, Paes B, Bont L, Manzoni P, Simões EAF, Fauroux B, et al. Defining the risk and associated morbidity and mortality of severe respiratory syncytial virus infection among infants with congenital heart disease. Infect Dis Ther. Infect Dis Ther. 2017;6:37-56.

7. Murray J, Bottle A, Sharland M, et al. Risk factors for hospital admission with RSV bronchiolitis in England: a population-based birth cohort study. PLoS ONE. 2014;9:e89186.

8. Robinson JL, Grenier D, MacLusky I, Allen UD. Respiratory syncytial virus infections in pediatric transplant patients: A Canadian Paediatric Surveillance Program study. Pediatr Transplant. 2015;19:659-62.

9. Hutspardol S, Essa M, Richardson S, Schechter T, Ali M, Krueger J, et al. Significant transplantation-related mortality from respiratory virus infections within the first one hundred days in children after hematopoietic stem cell transplantation. Biol Blood Marrow Transplant. 2015;21:1802-7.

10. Kristensen K, Hjuler T, Ravn H, Simões EA, Stensballe LG. Chronic diseases, chromosomal abnormalities, and congenital malformations as risk factors for respiratory syncytial virus hospitalization: a population-based cohort study. Clin Infect Dis. 2012;54:810-7.

11. Wilkesmann A, Ammann RA, Schildgen O, Eis-Hübinger AM, Müller A, Seidenberg J, et al. DSM RSV Ped Study Group. Hospitalized children with respiratory syncytial virus infection and neuromuscular impairment face an increased risk of a complicated course. Pediatr Infect Dis J. 2007;26:485-91.

12. Morris JK, Garne E, Wellesley D, Addor MC, Arriola $\mathrm{L}$, Barisic I, et al. Major congenital anomalies in babies born with Down syndrome: a EUROCAT population-based registry study. Am J Med Genet A. 2014;164A:2979-86.

13. Bergström S, Carr H, Petersson G, Stephansson O, Bonamy AK, Dahlström A, et al. Trends in congenital heart defects in infants with Down syndrome. Pediatrics. 2016;138:e20160123.

14. Figueras Aloy J. Respiratory syncytial virus and Down's syndrome. Rev Med Int Sindr Down. 2011;1:33.

15. Gooch KL, Vo PG, Khong H. Down syndrome (DS) without congenital heart disease (CHD) and the risk of hospitalization for a lower respiratory tract infection (LRTI) and LRTI due to respiratory syncytial virus. Acta Paediatr. 2011;100:24.

16. Zachariah P, Ruttenber M, Simões EA. Hospitalizations due to respiratory syncytial virus in children with congenital malformations. Pediatr Infect Dis J. 2011;30:442-5.

17. Mendoza Sanchez MC, Ruiz-Contreras J, Vivanco JL, Fernandez-Carrion F, Fernandez MB, Ramos JT, et al. Respiratory virus infections in children with cancer or HIV infection. J Pediatr Hematol Oncol. 2006;28:154-9.

18. Doucette A, Jiang X, Fryzek J, Coalson J, McLaurin K, Ambrose CS. Trends in respiratory syncytial virus and bronchiolitis hospitalization rates in high-risk infants in a United States nationally representative database, 1997-2012. PLoS ONE. 2016;11:e0152208.

19. Pockett RD, Campbell D, Carroll S, Rajoriya F, Adlard N. A comparison of healthcare resource use for rotavirus and RSV between vulnerable children with co-morbidities and healthy children: a case control study. J Med Econ. 2013;16:560-5.

20. El Saleeby CM, Somes GW, DeVincenzo JP, Gaur AH. Risk factors for severe respiratory syncytial virus disease in children with cancer: the importance of lymphopenia and young age. Pediatrics. 2008;121:235-43.

21. Moreno-Perez D, Calvo C, Five Study Group. Epidemiological and clinical data of hospitalizations 
associated with respiratory syncytial virus infection in children under 5 years of age in Spain: FIVE multicenter study. Influenza Other Respir Viruses. 2014;8:209-16.

22. Stagliano DR, Nylund CM, Eide MB, et al. Children with Down syndrome are high-risk for severe respiratory syncytial virus disease. J Pediatr. 2015;166:e2.

23. Fauroux B, Simões EAF, Checchia PA, Paes B, Figueras-Aloy J, Manzoni $\mathrm{P}$, et al. The burden and long-term respiratory morbidity associated with respiratory syncytial virus infection in early childhood. Infect Dis Ther. 2017;6:173-97.

24. OCEBM Levels of Evidence Working Group. The Oxford 2011 Levels of Evidence. Oxford Centre for Evidence-Based Medicine. http://www.cebm.net/ index.aspx?o=5653. Accessed Mar 2017.

25. OCEBM Levels of Evidence Working Group. The Oxford 2009 Levels of Evidence. Oxford Centre for Evidence-Based Medicine http://www.cebm.net/ oxford-centre-evidence-based-medicine-levelsevid ence-march-2009/. Accessed Mar 2017.

26. Viswanathan M, Berkman ND, Dryden DM, L Hartling. Assessing risk of bias and confounding in observational studies of interventions or exposures: further development of the RTI item bank. Methods Research Report. AHRQ Publication No.13-EHC106-EF. Rockville, MD: Agency for Healthcare Research and Quality; August 2013. http://www. effectivehealthcare.ahrq.gov/reports/final.cfm. Accessed Mar 2017.

27. Zachariah P, Ruttenber M, Simoes EA. Down syndrome and hospitalizations due to respiratory syncytial virus: a population-based study. J Pediatr. 2012;160:827-31.

28. Pisesky A, Benchimol EI, Wong CA, Hui C, Crowe $\mathrm{M}$, Belair MA, et al. Incidence of hospitalization for respiratory syncytial virus infection amongst children in Ontario, Canada: a population-based study using validated health administrative data. PLoS One. 2016;11:e0150416.

29. Sánchez-Luna M, Medrano C. Lirio J; RISK-21 Study Group. Down syndrome as risk factor for respiratory syncytial virus hospitalization: a prospective multicenter epidemiological study. Influenza Other Respir Viruses. 2017;11:157-64.

30. Medrano López C, García-Guereta Silva L, Lirio Casero J, García Pérez J, Grupo CIVIC, Grupo de Trabajo de Infecciones de la Sociedad Española de Cardiología Pediátrica y Cardiopatías Congénitas. Respiratory infections, Down's syndrome and congenital heart disease: the CIVIC 21 study. An Pediatr (Barc). 2009; 71:38-46.
31. Bloemers BL, van Furth AM, Weijerman ME, Gemke RJ, Broers CJ, van den Ende $K$, et al. Down syndrome: a novel risk factor for respiratory syncytial virus bronchiolitis-a prospective birth-cohort study. Pediatrics. 2007;120:e1076-81.

32. Fjaerli HO, Farstad T, Bratlid D. Hospitalisations for respiratory syncytial virus bronchiolitis in Akershus, Norway, 1993-2000: a population-based retrospective study. BMC Pediatr. 2004;4:25.

33. Chu HY, Chin J, Pollard J, Zerr DM, Englund JA. Clinical outcomes in outpatient respiratory syncytial virus infection in immunocompromised children. Influenza Other Respir Viruses. 2016;10:205-10.

34. Campbell AP, Guthrie KA, Englund JA, Farney RM, Minerich EL, Kuypers J, et al. Clinical outcomes associated with respiratory virus detection before allogeneic hematopoietic stem cell transplant. Clin Infect Dis. 2015;61:192-202.

35. Feldman AG, Beaty B, Sundaram S, Kempe A. Hospitalizations for respiratory syncytial virus, influenza, and other vaccine preventable illnesses in liver transplant recipients at freestanding US Children's Hospitals. Hepatology. 2015;62:279A.

36. El-Bietar J, Nelson AS, Wallace G, Dandoy CE, Jodele S, Myers KC, et al. Good outcome of RSV infection without ribavirin treatment in pediatric bone marrow transplantation. Biol Blood Marrow Transplant. 2015;21:S206-39.

37. Chemaly RF, Ghantoji SS, Shah DP, Shah JN, El Taoum KK, Champlin RE, et al. Respiratory syncytial virus infections in children with cancer. J Pediatr Hematol Oncol. 2014;36:e376-81.

38. Tran TT, Gonzalez IA, Tekin A, McLaughlin GE. Lower respiratory tract viral infections in pediatric abdominal organ transplant recipients: a single hospital inpatient cohort study. Pediatr Transplant. 2013;17:461-5.

39. Lo MS, Lee GM, Gunawardane N, Burchett SK, Lachenauer CS, Lehmann LE. The impact of RSV, adenovirus, influenza, and parainfluenza infection in pediatric patients receiving stem cell transplant, solid organ transplant, or cancer chemotherapy. Pediatr Transplant. 2013;17:133-43.

40. Sung L, Alonzo TA, Gerbing RB, Aplenc R, Lange BJ, Woods WG, et al. Respiratory syncytial virus infections in children with acute myeloid leukemia: A report from the Children's Oncology Group. Pediatr Blood Cancer. 2008;51:84-6.

41. Miller RB, Chavers BM. Respiratory syncytial virus infections in pediatric renal transplant recipients. Pediatr Nephrol. 1996;10:213-5. 
42. Wang EE, Law BJ, Stephens D. Pediatric Investigators Collaborative Network on Infections in Canada (PICNIC) prospective study of risk factors and outcomes in patients hospitalized with respiratory syncytial viral lower respiratory tract infection. J Pediatr. 1995;126:212-9.

43. Luján-Zilbermann J, Benaim E, Tong X, Srivastava DK, Patrick CC, DeVincenzo JP. Respiratory virus infections in pediatric hematopoietic stem cell transplantation. Clin Infect Dis. 2001;33:962-8.

44. Liu M, Worley S, Arrigain S, Aurora P, Ballmann M, Boyer D, Conrad C, et al. Respiratory viral infections within one year after pediatric lung transplant. Transpl Infect Dis. 2009;11:304-12.

45. Small TN, Casson A, Malak SF, Boulad F, Kiehn TE, Stiles J, et al. Respiratory syncytial virus infection following hematopoietic stem cell transplantation. Bone Marrow Transplant. 2002;29:321-7.

46. Blanchard SS, Gerrek M, Siegel C, Czinn SJ. Significant morbidity associated with RSV infection in immunosuppressed children following liver transplantation: case report and discussion regarding need of routine prophylaxis. Pediatr Transplant. 2006;10:826-9.

47. Asner S, Stephens D, Pedulla P, Richardson SE, Robinson J, Allen U. Risk factors and outcomes for respiratory syncytial virus-related infections in immunocompromised children. Pediatr Infect Dis J. 2013;32:1073-6.

48. Simon A, Muller A, Khurana K, Engelhart S, Exner M, Schildgen O, DSM RSV Paed Study Group, et al. Nosocomial infection: a risk factor for a complicated course in children with respiratory syncytial virus infection-results from a prospective multicenter German surveillance study. Int J Hyg Environ Health. 2008;211:241-50.

49. Simon A, Schildgen O, Panning M, Bode U, Eis-Huebinger AM. Respiratory syncytial virus infection in patients with cancer: still more questions than answers. Clin Infect Dis. 2008;46:1933-4.

50. Anak S, Atay D, Unuvar A, Garipardic M, Agaoglu L, Ozturk G, et al. Respiratory syncytial virus infection outbreak among pediatric patients with oncologic diseases and/or BMT. Pediatr Pulmonol. 2010;45:307-11.

51. McCarthy AJ, Kingman HM, Kelly C, Taylor GS, Caul EO, Grier D, et al. The outcome of 26 patients with respiratory syncytial virus infection following allogeneic stem cell transplantation. Bone Marrow Transplant. 1999;24:1315-22.

52. Avetisyan G, Mattsson J, Sparrelid E, Ljungman P. Respiratory syncytial virus infection in recipients of allogeneic stem-cell transplantation: a retrospective study of the incidence, clinical features, and outcome. Transplantation. 2009;88:1222-6.

53. Alvaro G, Zuccotti GV. Epidemiological aspects of respiratory syncytial virus (RSV) infections in Italy: a national survey. J Int Med Res. 2000;28:207-13.

54. Ernst J, Sauerbrei A, Krumbholz A, Egerer R, Mentzel HJ, Kurzai M, et al. Multiple viral infections after haploidentical hematopoietic stem cell transplantation in a child with acute lymphoblastic leukemia. Transpl Infect Dis. 2012;14:E82-8.

55. Vettenranta K, Ukkonen P, Saarinen UM. RSV infection complicating the therapy of pediatric malignancies: report of six cases. Med Pediatr Oncol. 1996;26:261-3.

56. El Saleeby CM, Bush AJ, Harrison LM, Aitken JA, Devincenzo JP. Respiratory syncytial virus load, viral dynamics, and disease severity in previously healthy naturally infected children. J Infect Dis. 2011;1:996-1002.

57. Chu HY, Englund JA, Podczervinski S, Kuypers J, Campbell AP, Boech M, et al. Nosocomial transmission of respiratory syncytial virus in an outpatient cancer center. Biol Blood Marrow Transplant. 2014;20:844-51.

58. von Renesse A, Schildgen O, Klinkenberg D, Müller A, von Moers A, Simon A, DSM RSV Study Group. Respiratory syncytial virus infection in children admitted to hospital but ventilated mechanically for other reasons. J Med Virol. 2009;81:160-6.

59. Kim YJ, Guthrie KA, Waghmare A, Walsh EE, Falsey AR, Kuypers J, et al. Respiratory syncytial virus in hematopoietic cell transplant recipients: factors determining progression to lower respiratory tract disease. J Infect Dis. 2014;209:1195-204.

60. Arnold SR, Wang EE, Law BJ, Boucher FD, Stephens $\mathrm{D}$, Robinson JL, et al. Variable morbidity of respiratory syncytial virus infection in patients with underlying lung disease: a review of the PICNIC RSV database. Pediatric Investigators Collaborative Network on Infections in Canada. Pediatr Infect Dis J. 1999;18:866-9.

61. Deschamp AR, Gebregziabher N, Yu Z, Ranganathan SC, Ferkol TW, Davis SD. Prevalence of respiratory viral infections in infants with cystic fibrosis diagnosed by Newborn screen. Am J Respir Crit Care Med. 2015;191:A3330.

62. Garcia DF, Hiatt PW, Jewell A, Schoonover SL, Cron SG, Riggs M, et al. Human metapneumovirus and respiratory syncytial virus infections in older children with cystic fibrosis. Pediatr Pulmonol. 2007;42:66-74. 
63. Hiatt PW, Grace SC, Kozinetz CA, Raboudi SH, Treece DG, Taber LH, et al. Effects of viral lower respiratory tract infection on lung function in infants with cystic fibrosis. Pediatrics. 1999;103:619-26.

64. Somayaji R, Goss CH, Khan U, Neradilek M, Neuzil KM, Ortiz JR. Cystic fibrosis pulmonary exacerbations attributable to respiratory syncytial virus and influenza: a population-based study. Clin Infect Dis. 2017;64:1760-7.

65. Van Ewijk BE, Wolfs TF, Aerts PC, Van Kessel KP, Fleer A, Kimpen JL, et al. RSV mediates Pseudomonas aeruginosa binding to cystic fibrosis and normal epithelial cells. Pediatr Res. 2007;61:398-403.

66. de Vrankrijker AM, Wolfs TF, Ciofu O, Høiby N, van der Ent CK, Poulsen SS, et al. Respiratory syncytial virus infection facilitates acute colonization of Pseudomonas aeruginosa in mice. J Med Virol. 2009;81:2096-103.

67. Doering G, Gusenleitner W, Belohradsky BH, Burdach S, Resch B, Liese JG. The risk of respiratory syncytial virus-related hospitalizations in preterm infants of 29 to 35 weeks' gestational age. Pediatr Infect Dis J. 2006;25:1188-90.

68. Kristensen K, Dahm T, Frederiksen PS, Ibsen J, Iyore E, Jensen AM, et al. Epidemiology of respiratory syncytial virus infection requiring hospitalization in East Denmark. Pediatr Infect Dis J. 1998;17:996-1000.
69. Purcell K, Fergie J. Driscoll Children's Hospital respiratory syncytial virus database: risk factors, treatment and hospital course in 3308 infants and young children, 1991 to 2002 . Pediatr Infect Dis J. 2004;23:418-23.

70. Calvo C, Moreno-Pérez D, Grupo de Estudio FIVE. Epidemiology and clinical evidence of infection by respiratory syncytial virus in children over 2 of age. National multicenter study (FIVE). Acta Pediatr Esp. 2015;73:5-9.

71. Bate J, Ladhani S, Sharland M, Chisholm J, Lamagni $\mathrm{T}$, Ramsay $\mathrm{M}$, et al. Infection-related mortality in children with malignancy in England and Wales, 2003-2005. Pediatr Blood Cancer. 2009;53:371-4.

72. Lerret S, Mavis A, Biank V, Telega G. Respiratory syncytial virus and pediatric liver transplant: one center's experience. Prog Transplant. 2013;23:253-7.

73. Thorburn K. Pre-existing disease is associated with a significantly higher risk of death in severe respiratory syncytial virus infection. Arch Dis Child. 2009;94:99-103.

74. Byington CL, Wilkes J, Korgenski K, Sheng X. Respiratory syncytial virus-associated mortality in hospitalized infants and young children. Pediatrics. 2015;135:e24-31. 